\title{
Detailed dayside auroral morphology as a function of local time for southeast IMF orientation: implications for solar wind-magnetosphere coupling
}

\author{
P. E. Sandholt ${ }^{1}$, C. J. Farrugia ${ }^{2}$, and W. F. Denig ${ }^{3}$ \\ ${ }^{1}$ Department of Physics, University of Oslo, Oslo, Norway \\ ${ }^{2}$ Space Science Center, University of New Hampshire, Durham, New Hampshire, USA \\ ${ }^{3}$ Space Vehicles Directorate, Air Force Research Laboratory, Hanscom AFB, Massachusetts, USA
}

Received: 1 March 2004 - Revised: 15 June 2004 - Accepted: 24 June 2004 - Published: 3 November 2004

\begin{abstract}
In two case studies we elaborate on spatial and temporal structures of the dayside aurora within 08:00-16:00 magnetic local time (MLT) and discuss the relationship of this structure to solar wind-magnetosphere interconnection topology and the different stages of evolution of open field lines in the Dungey convection cycle. The detailed 2-D auroral morphology is obtained from continuous ground observations at $\mathrm{Ny}$ Ålesund $\left(76^{\circ}\right.$ magnetic latitude (MLAT)), Svalbard during two days when the interplanetary magnetic field (IMF) is directed southeast $\left(B_{y}>0 ; B_{z}<0\right)$. The auroral activity consists of the successive activations of the following forms: (i) latitudinally separated, sunward moving, arcs/bands of dayside boundary plasma sheet (BPS) origin, in the prenoon (08:00-11:00 MLT) and postnoon (12:0016:00 MLT) sectors, within 70-75 ${ }^{\circ}$ MLAT, (ii) poleward moving auroral forms (PMAFs) emanating from the pre- and postnoon brightening events, and (iii) a specific activity appearing in the 07:00-10:00 MLT/75-80 ${ }^{\circ}$ MLAT during the prevailing IMF $B_{y}>0$ conditions. The pre- and postnoon activations are separated by a region of strongly attenuated auroral activity/intensity within the 11:00-12:00 MLT sector, often referred to as the midday gap aurora. The latter aurora is attributed to the presence of component reconnection at the subsolar magnetopause where the stagnant magnetosheath flow lead to field-aligned currents (FACs) which are of only moderate intensity. The much more active and intense aurorae in the prenoon (07:00-11:00 MLT) and postnoon (12:0016:00 MLT) sectors originate in magnetopause reconnection events that are initiated well away from the subsolar point. The high-latitude auroral activity in the prenoon sector (feature iii) is found to be accompanied by a convection channel at the polar cap boundary. The associated ground magnetic deflection (DPY) is a Svalgaard-Mansurov effect. The convection channel is attributed to effective momentum trans-
\end{abstract}

Correspondence to: P. E. Sandholt

(p.e.sandholt@fys.uio.no) fer from the solar wind-magnetosphere dynamo in the highlatitude boundary layer (HBL), on the downstream side of the cusp.

Key words. Magnetospheric physics (auroral phenomena: magnetopause, cusp and boundary layers; solar windmagnetosphere interactions)

\section{Introduction}

This study deals with auroral signatures of temporal and spatial aspects of solar wind-magnetosphere-ionosphere coupling processes which are in operation during intervals of southward directed interplanetary magnetic field (IMF) when a significant east-west $\left(B_{y}\right)$ component is also present. The spatial aspect is closely related to the IMF $B_{y}$ regulated dawn-dusk asymmetry of the dayside magnetosphere (Jørgensen et al., 1972; Cowley, 1981; Gosling et al., 1990), appearing strongly in plasma convection (Mozer et al., 1974; Heppner and Maynard, 1987; Cowley et al., 1991; Weimer, 1995), auroral precipitation and field-aligned currents (Potemra and Saflekos, 1979; Friis-Christensen, 1984; Taguchi et al., 1993; Watanabe et al., 1996; Farrugia et al., 2003), while the temporal aspect refers to the pulsed nature of the magnetopause reconnection process (Russell and Elphic, 1978). The spatial aspect we study includes the role played by the high-latitude boundary layer (HBL) in the $B_{y}$-regulated solar wind-magnetosphere coupling (Siscoe et al., 2000) in the Dungey convection cycle, giving rise to a Svalgaard-Mansurov effect in ground magnetic deflections (Svalgaard, 1973).

In previous studies of the dayside aurora based on groundand/or space-based observations attention has been directed mainly on the temporal structure. This approach has given us important insight on the coupling of temporal features of the magnetopause reconnection process (flux transfer events; 
FTEs) to the ionosphere (Sandholt et al., 1990, 1993b; Milan et al., 2000; Neudegg et al., 2001; Sandholt et al., 2003; Lockwood et al., 2003). A major issue under debate in magnetospheric physics today is the magnetopause reconnection topology (Moore et al., 2002; Russell, 2003; Maynard et al., 2003). The investigation of the spatial structure of the dayside aurora is in our view very relevant to this issue. Up to now many studies of the spatial structure have been severely hampered by the restricted field of view (FOV) provided by single ground instruments and/or by the poor spatial resolution in the space-based observations.

In a few case studies the FOV has been extended by the combination of data from similar instruments located at different sites, providing partly overlapping fields of view (Sandholt et al., 2003). In a few other cases the limited ground perspective has been combined with space-based auroral observations (Farrugia et al., 2004b). The latter approach is very useful and promising, but only very few data sets of this type have been studied so far. Thus, despite the various efforts that have been made over the years to improve the spatial resolution and coverage, the present description of the dayside auroral morphology is still fragmentary. As indicated above, this is mainly due to the restricted spatial coverage of the ground observations and to the poor spatial resolution in the space-based observations.

In the present study we extend the ground perspective (spatial coverage) by applying a long series of observations from a single station as it sweeps through the entire dayside from 08:00 to 15:00 MLT on 3 December 1997 and 12 December 1999. This approach is particularly relevant since the interplanetary magnetic field (IMF) orientation, as represented by the clock angle in the Y-Z plane, remained in the same sector $\left(90-150^{\circ} ; B_{z}<0 ; B_{y}>0\right)$ most of the time during these two days. Thus, we can provide an updated description of the detailed dayside auroral morphology as a function of local time (MLT) for this particular regime of IMF orientation. Under the actual IMF condition a distinct component of the ground magnetic deflection is of the type referred to as DPY (Friis-Christensen and Wilhjelm, 1975), or the Svalgaard-Mansurov effect (Svalgaard, 1973). An important aspect of this study is the demonstration of the association between the dayside aurora and a polar cap convection channel, giving rise to a Svalgaard-Mansurov effect. For this purpose we shall apply ion drift data from spacecraft DMSP F13. Particle precipitation data obtained from three DMSP spacecraft are used to identify the plasma sources of the various auroral forms.

Very different reconnection topologies and associated ionospheric signatures are predicted for the different reconnection models during conditions involving an IMF with a strong east/west $\left(B_{y}\right)$ component. It is therefore of great interest to document the detailed spatial structure of the dayside aurora in such cases.

First, we shall give a brief description of three different reconnection topologies for the case of southeast or southwest IMF orientations. Case (I) is the component reconnection model (Sonnerup, 1974; Gonzalez and Mozer, 1974; Hill,
1975; Cowley, 1976; Moore et al., 2002), according to which there is no strong restriction on the magnetic shear between the external and internal fields, except perhaps for a cutoff at shear angles below $\sim 40^{\circ}$ (Phan and Paschmann, 1996). In this case reconnection in the subsolar region is present along a tilted reconnection line. Until a few years ago this was the majority view even as a result of the success in interpretation of data from ISEE 1 and 2, which crossed the magnetopause at typically low latitudes and which gave the first evidence for the occurrence of reconnection (Paschmann et al., 1978, 1979; Sonnerup et al., 1981).

In contrast to case (I), the antiparallel reconnection hypothesis, which is our case (II), limits the process to regions of field shear close to $180^{\circ}$ (Crooker, 1979; Luhmann et al., 1984). In this case, for an IMF pointing southeast/west, reconnection is absent in the subsolar region, but is present simultaneously at high northern (southern) latitudes in the postnoon (prenoon) sector and at high southern (northern) latitudes in the prenoon sector during positive (negative) IMF $B_{y}$ conditions.

Substantial differences in ionospheric footprints of the reconnection process are expected in these two scenarios in the form of plasma convection (Coleman et al., 2001; Chisham et al., 2002a; Rodger et al., 2003) and auroral precipitation (Newell et al., 1995; Maynard et al., 2001; Sandholt et al., 2004). In case II, IMF $B_{y}$ bifurcates the cusp longitudinally due to the split (two-branch) X-line topology (Crooker, 1979; Luhmann et al., 1984). As a consequence there is a substantive subsolar region where there is no reconnected flux and hence no evidence of an open low-latitude boundary layer (Rodger et al., 2003).

Thus, in case II and for positive $B_{y}$ conditions, the reconnection site is shifted to high northern latitudes in the postnoon sector and to high southern latitudes in the prenoon sector for $B_{y}$ positive conditions. Observations indicating the occurrence of reconnection, in the form of flux transfer events (FTEs), at high magnetopause latitudes have been reported by Haerendel et al. (1978). The antiparallel reconnection topology was also considered by Rijnbeek (1984) to be a possible interpretation of certain FTEs observed by spacecraft HEOS 2 at high latitudes. Magnetohydrodynamic (MHD) simulations indicating that antiparallel reconnection is ocurring have been reported by, for example, White et al. (1998) and Peroomian (2003).

In a third possible reconnection topology (case III), the process may occur simultaneously in different modes/rates in different sectors along a tilted X-line running through the subsolar region and extending to high latitudes (see, e.g. Fig. 4 of Moore et al., 2002). In this model reconnection is of the component type in the subsolar region and antiparallel at high latitudes in the northern dusk (dawn) and southern dawn (dusk) sectors for positive (negative) IMF $B_{y}$ conditions (see also Siscoe et al., 2001).

In the model of Luhmann et al. (1984) (case II), reconnection is limited to conditions of near-antiparallel fields. Thus, this model may also allow for a small guide field along the reconnection line. The latter may be important for 
the formation of reconnected flux tubes in bursty reconnection (FTEs). Recall that, considering the continuity of the field component normal to the magnetopause, $B_{N}$, Cowley (1982), and, independently, Paschmann et al. (1982) postulated a twisted field in the reconnected flux tube. Saunders et al. (1984) gave two-spacecraft examples verifying this idea observationally. Later, Lee and Fu (1985) incorporated this idea as an essential feature in their model, but extended it to include multiple $\mathrm{X}$-lines.

In recent years there has been an intense search for ionospheric signatures of antiparallel merging. Modelling work on the ionospheric footprint of the antiparallel X-line topology has been reported by Coleman et al. (2001) and by Rodger et al. (2003), who mapped the antiparallel merging region (X-line) to the ionosphere, using the Tsyganenko (1996) field line mapping for an IMF condition characterized by $B_{z}=-3 \mathrm{nT}$ and $B_{y}=3 \mathrm{nT}$ (clock angle in the GSM Y-Z plane $=135^{\circ}$ ). They found a small gap in the ionospheric footprint at noon under conditions very similar to those we study: December solstice in the Northern Hemisphere (see below). The convection signature is manifest in the form of a limited region in the midday sector, where the ion flow signature is very weak at a time when there are strong flows on either side of it, in the prenoon and postnoon convection cells (see Fig. 5 in Chisham et al., 2002a, and Fig. 8 in Chisham et al., 2002b).

Elements of interpretation of the dayside auroral morphology reported in this study, which is representative of a southeast $\left(B_{y}>0\right)$ IMF orientation, are as follows:

(A) The midday gap aurora and the subsolar magnetopause: Component reconnection in the subsolar region gives rise to an open low-latitude boundary layer (LLBL). Field-aligned current generation in the open LLBL is strongly related to the local flow shear (Sonnerup and Siebert, 2003). This flow shear reaches a minimum at the stagnant, subsolar magnetopause (Spreiter et al., 1966; Russell et al., 1981), giving rise to a corresponding minimum in FAC intensity around noon (11:00-12:00 MLT sector in our case) and the associated midday gap aurora.

(B) Pre- and postnoon auroral brightening events threaded by newly-open field lines: These forms are attributed to the presence of antiparallel (or near-antiparallel) reconnection in different hemispheres (prenoon/south and postnoon/north), as envisaged by Luhmann et al. (1984). Strong flow shears in the pre- and postnoon boundary layers give rise to strong FAC intensities in these sectors (away from noon) and associated enhanced auroral intensity there.

(C) High-latitude auroral events in the prenoon sector (07:00-11:00 MLT/75-80 $0^{\circ}$ MLAT) threaded by old open field lines: They are accompanied by a channel of strong plasma convection and the associated DPY magnetic deflection, a Svalgaard-Mansurov effect (Svalgaard, 1973). This specific aurora and plasma convection are manifestations of high-latitude momentum transfer events on the downstream side of the cusp.

(D) High-latitude auroral form (polar arc; see also Lyons et al., 1996) in the postnoon sector (13:00-16:00 MLT): This

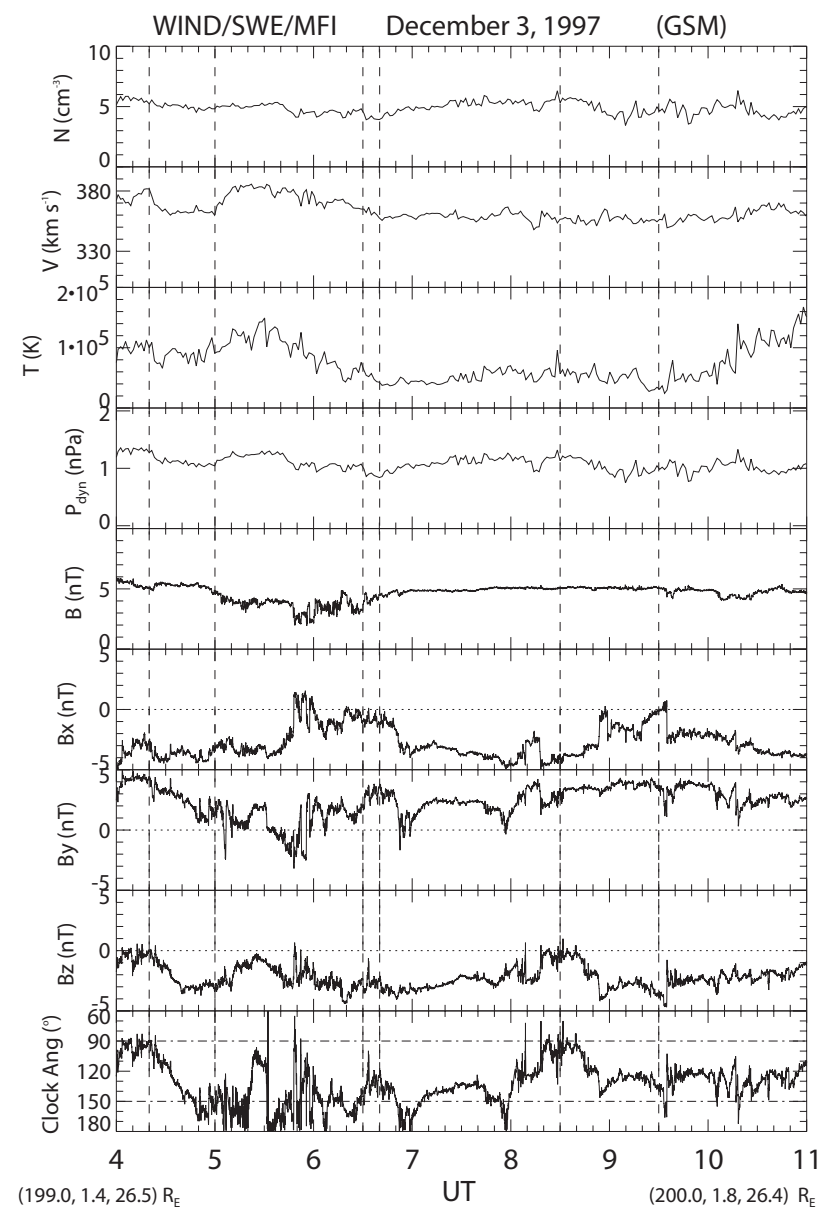

Fig. 1. Solar wind plasma and IMF observations from spacecraft Wind during the interval 04:00-01:00 UT on 3 December 1997. Panels from top to bottom shows proton density, bulk speed, temperature, solar wind dynamic pressure, the total field intensity and the GSM components $\left(B_{x}, B_{y}\right.$, and $\left.B_{z}\right)$ of the interplanetary magnetic field (IMF). The three selected intervals for which we report/discuss dayside auroral observations are indicated by vertical guidelines.

aurora is located in a region of flow shear (see Reiff et al., 1978), well poleward of the R1 current, i.e. between this current and the regime of polar rain precipitation. Lobe reconnection is a candidate source (Reiff and Burch, 1985; Eriksson et al., 2002, 2003).

The paper is organized as follows. The presentation of the observations, including solar wind plasma and IMF parameters, the optical aurora obtained from ground-based instrumentation, satellite observations of particle precipitation and ionospheric ion drift, and ground magnetic deflections, representing two cases/days, is followed by a summary of the observations, a discussion section, and a final list of conclusions. 


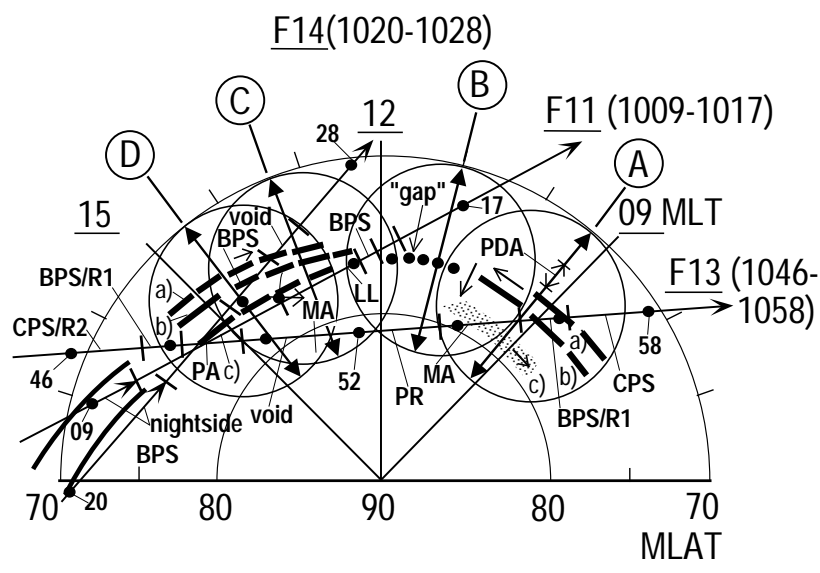

Fig. 2. Schematic illustration of dayside auroral configuration applicable to the interval 05:50-11:00 UT on 3 December 1997. The coordinate system is MLAT/MLT. The fields of view at $630.0 \mathrm{~nm}$ of the MSP and all-sky camera (ASC) in Ny Ålesund for 05:50 UT (A), 07:40 UT (B), 09:50 UT (C), and 10:50 UT (D) are marked by double-arrowed meridional lines and circle, respectively. The tracks of DMSP spacecraft F11, F13, and F14 during the intervals 10:09-10:17 (F11), 10:20-10:28 UT (F14), and 10:46-10:58 (F13), respectively, are indicated. Precipitation regimes are marked along the tracks. Multiple, fragmented BPS arcs in the pre- and postnoon sectors are marked $a, b$, as well as directions of auroral motion (arrows). A deep minimum of auroral intensity in the $\sim$ 11:00-12:00 MLT sector is marked with solid dots.

\section{Data presentation}

\subsection{Case 1: 3 December 1997}

\subsubsection{IMF and solar wind plasma data}

Figure 1 shows solar wind plasma and IMF observations obtained from spacecraft Wind during the interval 04:0011:00 UT on 3 December 1997. The positions of Wind at 04:00 and 11:00 UT are (199.0; 1.4; 26.5) $R_{E}$ and (200.0; 1.8 ; 26.4) $R_{E}$. The Wind-to-ground propagation delay is estimated to be $\sim 58 \mathrm{~min}$. The latter estimate is based on the observed auroral responses to the southward and northward rotations of the IMF recorded by Wind at 04:30-04:50 UT and 08:18 UT, respectively. Vertical guidelines delimit the intervals 04:20-05:00 UT, 06:30-06:40 UT, and 08:30-09:30 UT, corresponding to three of the selected intervals of auroral observations which are discussed below, when the ground auroral station swept through the following local time sectors 04:20-05:00 MLT, 11:00 MLT, and 13:00-14:00 MLT. The solar wind and IMF conditions are very similar in these intervals. They are characterized by a slow solar wind speed $(360 \mathrm{~km} / \mathrm{s})$, normal field strength $(5 \mathrm{nT})$, slightly below normal dynamic pressure $(\sim 1 \mathrm{nPa})$, negative $B_{x}$, positive $B_{y}$, and negative $B_{z}$. The IMF clock angle regime is $90-150^{\circ}$.

\subsubsection{Overview of the auroral observations}

The observation geometry for this case, as well as some main features of the auroral observations obtained from $\mathrm{Ny}$ Ålesund during the interval 05:50-11:00 UT on 3 December 1997, are indicated schematically in Fig. 2. Approximate fields of view of the meridian scanning photometer (MSP) and the ASC are marked A (05:50 UT), B (07:40 UT), C (09:50 UT), and D (10:50 UT). The multiple, fragmented BPS arcs in the prenoon ( 08:00-10:00 MLT) and postnoon $(\sim 12: 30-16: 00$ MLT) sectors, characterized by noonward motions (see arrows), are shown (labels a and b), as well as the "midday gap aurora" (solid dots) in the $\sim 11: 00-12: 00$ MLT sector. Particle precipitation/fieldaligned current regimes are marked by bars along the tracks of DMSP spacecraft F11, F13, and F14 during the intervals 10:09-10:17 UT (F11), 10:20-10:28 UT (F14), and 10:4610:58 UT (F 13). These intervals were selected in order to demonstrate typical features of the aurora in the pre-noon, midday, and postnoon sectors.

The prenoon sector perspective reveals, in addition to the BPS arcs located in the vicinity of $75^{\circ}$ MLAT, the presence of a pulsed, diffuse aurora (PDA) to the south, within the regime of CPS precipitation, and a pulsing cusp/mantle (MA) aurora in the north (form c). For a detailed description of the auroral activity within the field of view marked A in Fig. 2 we refer to Farrugia et al. (2003) (see their Figs. 9, 12, and 13). The plasma sources and FAC regimes associated with these aurorae, as observed from spacecraft Polar, are also reported in Farrugia et al. (2003). The IMF regulation of the prenoon sector auroral activity during the prevailing IMF $B_{y}>0$ conditions has also been reported in Sandholt et al. (2004). In this case presentation we shall focus on the following features: (i) the high-latitude activity in the prenoon sector (form c), (ii) the postnoon sector activity, and (iii) the phenomenon of midday gap aurora in the $\sim 11: 00$ 12:00 MLT sector. The latter is characterized by a deep minimum in auroral intensity/activity when compared with the pre- and postnoon sector activities.

\subsubsection{Auroral observations in detail}

Figure 3 shows stacked plots of the meridian scanning photometer (MSP) observations at 630.0 and $557.7 \mathrm{~nm}$ obtained at Ny Ålesund during the interval 05:55-11:00 UT on 3 December 1997. These observations illustrate both spatial and temporal variability of the dayside aurora as observed along the local magnetic meridian, within the $\sim 70-82^{\circ}$ MLAT range, as the station rotates with the Earth from morning through midday to postnoon magnetic local times. We note the following features: (i) strong, multiple (latitudinally separated) forms, appearing in both wavelength channels, lasting until 07:20 UT (10:50 MLT; interval I), (ii) one single form located close to zenith (both channels), with weaker emission towards north during 07:30-07:50 UT (interval II), (iii) midday gap aurora, characterized by reduced red line intensity and very weak green line emission, during the interval 


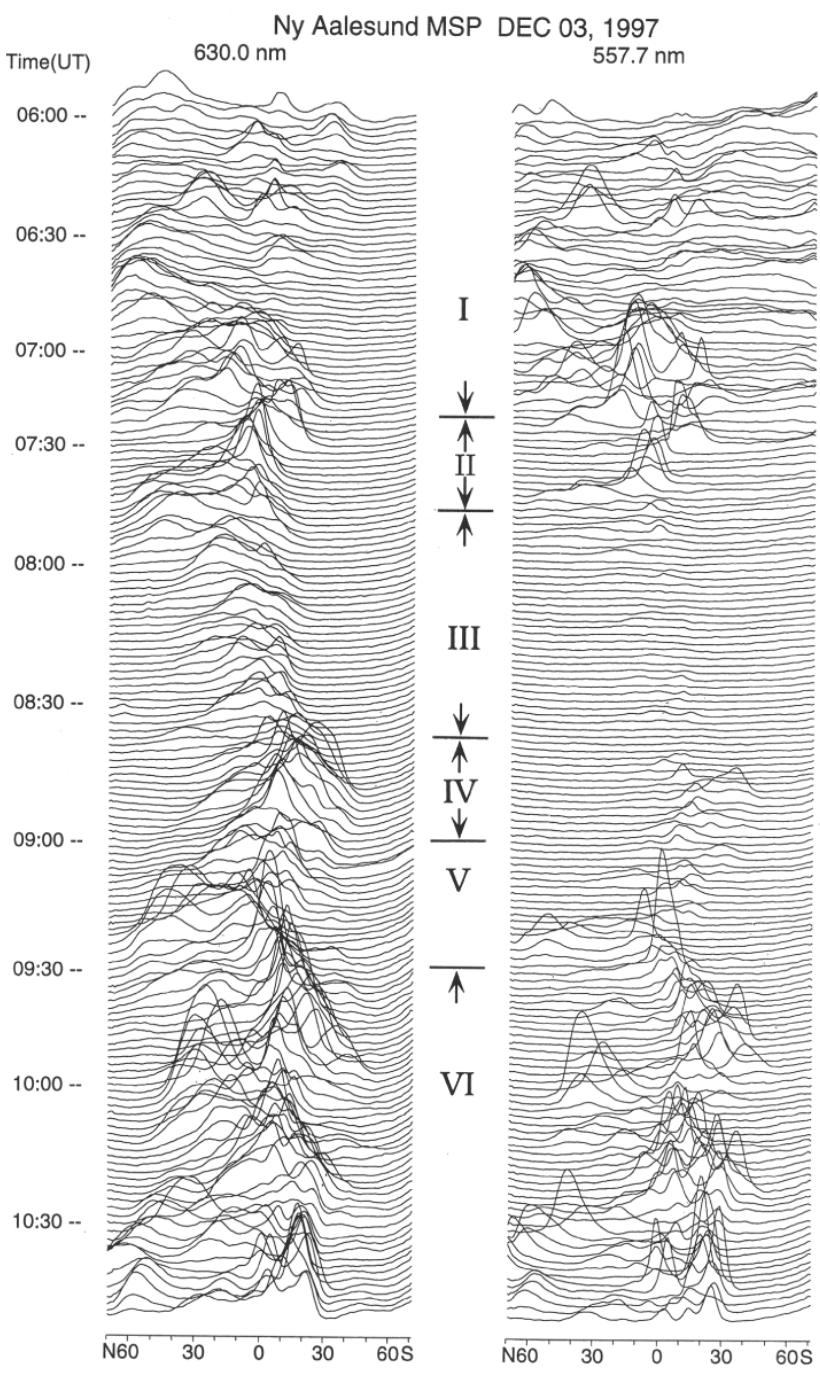

Fig. 3. Meridian scanning photometer (MSP) observations from $\mathrm{Ny}$ Ålesund during the interval 05:55-11:00 UT. Left and right columns show stacked plots of line of sight intensity vs. zenith angle for the wavelength channels at 630.0 and $557.7 \mathrm{~nm}$, respectively. Intervals showing different auroral characteristics are marked.

07:50-08:40 UT (11:20-12:10 MLT; interval III), (iv) equatorward boundary intensifications (EBIs), appearing most prominently in the red line emission, and associated equatorward expansion during 08:40-09:00 UT (interval IV), (v) poleward boundary intensifications (PBIs) in interval $\mathrm{V}$, and (vi) interval VI (09:30-11:00 UT) characterized by alternatively EBIs and PBIs, and associated equatorward and poleward expansions of the equatorward boundary. EBIs and PBIs in interval VI are strong in both emissions. The 2-D aspects of these activities, shown schematically in Fig. 2, will be documented with all-sky camera (ASC) observations below.

The detailed 2-D aspects of the auroral activity within the field of view marked (A) in Fig. 2 have been documented in Farrugia et al. (2003). Different auroral forms from lower to higher latitudes are marked in Fig. 2: (i) pulsed diffuse aurora (PDA), (ii) discrete forms a and b characterized by eastward (noonward) moving luminosity structures, and (iii) form c. The latter form appears as a sequence of brightening events, each of which is moving westward (antisunward), as indicated by arrow.

The auroral observations during intervals II and III in Fig. 3 are summarized by perspective (B) in Fig. 2. A representative ASC sequence is shown in Fig. 4. The evolution of the event during this interval (07:34-07:44 UT) shows a brightening appearing in the western part of the field of view, which is followed by rapid eastward expansion during 07:34-07:38 UT, and then a poleward expansion during 07:40-07:44 UT. This 2-phase evolution is marked by arrows in Fig. 2. The last image, representing 07:44 UT (lower right), shows the presence of bright forms at the eastern and western boundaries of the FOV, with a "gap" in the center.

ASC camera observations representing perspective (C) in Fig. 2 are shown in Fig. 5. This figure, representing the interval 09:50-09:58 UT, shows the successive activation/westward expansion of three latitudinally separated forms. These three forms are referred to as (a) (lowest latitude), (b), and (c) (highest latitude) in Fig. 2. A colour-coded contour plot of the meridian scanning photometer data for this event, which nicely confirms the successive activations of the three forms, will be shown below.

Figure 6 shows the ASC observations at $557.7 \mathrm{~nm}$ of the subsequent auroral activation taking place during 10:14 10:19 UT. We note the high degree of fragmentation, also in the direction along the forms. Brightenings are moving from east to west along these forms which are closely spaced in latitude.

Figure 7 shows the ASC observations at $557.7 \mathrm{~nm}$ for the interval 10:25-10:29 UT. While auroral forms (a) and (b) (see Fig. 2) intersect the MSP meridian south of zenith, the highest-latitude form (c) intersects to the north of zenith (to the right in the figure). It is seen that form (c) expanded westward and poleward during this 4-min long interval. At 10:29 UT (right panel) form (c) is brightest on the western side of the local MSP meridian. Thus, form (c) expanded across the MSP field of view (local magnetic meridian) during the interval 10:26-10:29 UT. This is clearly reflected in the MSP data shown in Fig. 8 (see panel b). This MSP figure is included in order to document the detailed spatiotemporal structure of the aurora, in particular the sequential activations of forms and the equatorward boundary motions. The former phenomenon is most clearly seen during interval 09:50-09:58 UT (compare ASC sequence in Fig. 5). The same sequential activation of latitudinally separated forms is seen during the interval 10:20-10:30 UT (compare ASC sequence in Fig. 7). Intervals characterized by equatorward expansion of the auroral equatorward boundary are 09:3509:50 UT and 10:10-10:25 UT. These intervals are separated by a 10-min long interval of weaker auroral intensity, which is accompanied by poleward retraction of the equatorward boundary. The strong brightening event located well to the north of zenith $\left(30-40^{\circ} \mathrm{NZ}\right)$ is our form (c). 


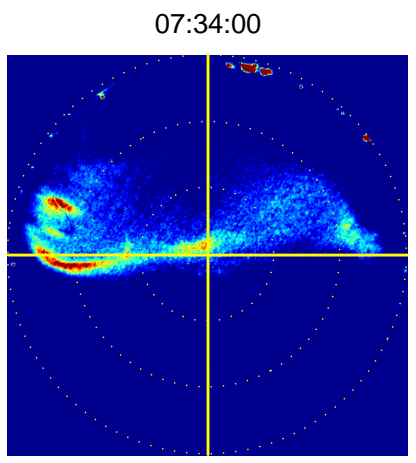

07:40:00

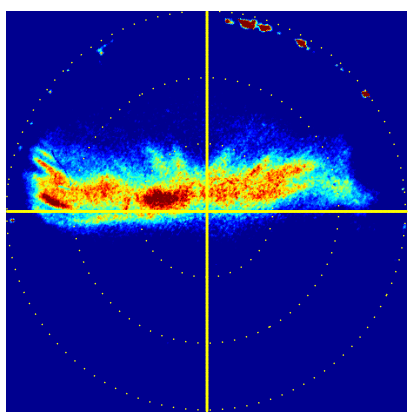

07:36:00

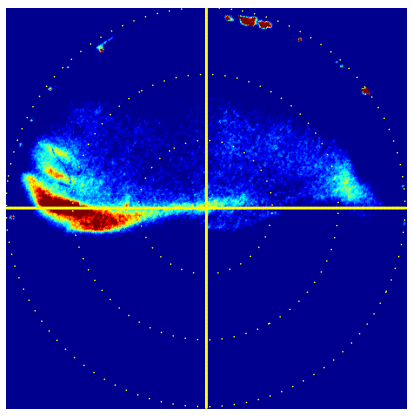

07:42:00

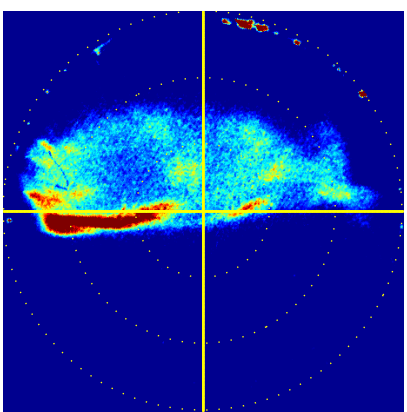

07:38:00

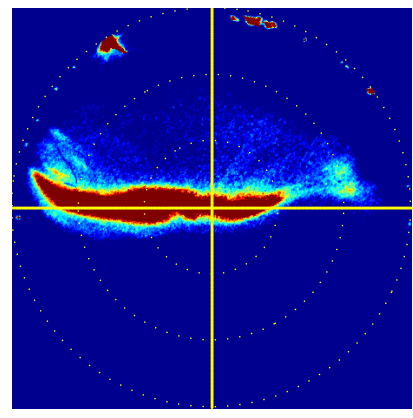

07:44:00

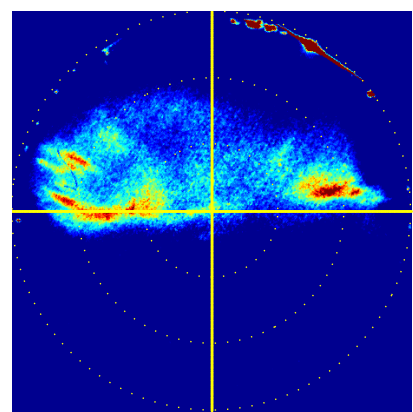

Fig. 4. Ny Ålesund ASC observations at $630.0 \mathrm{~nm}$ during the interval 07:34-07:44 UT on 3 December 1997. The reference frame is zenith angle (dotted circles at 30,60, and $90^{\circ}$ ) and azimuth. The MSP scanning meridian (magnetic meridian) is marked by the vertical yellow line. North is up. West is to the left. The integration time is $2 \mathrm{~s}$.

09:50:01

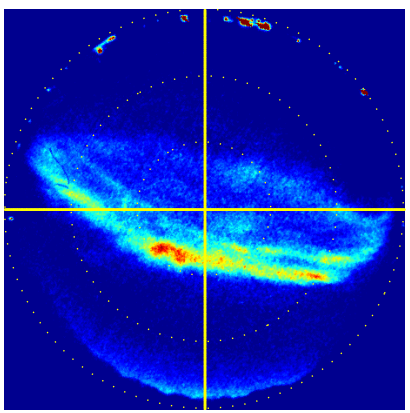

09:56:01

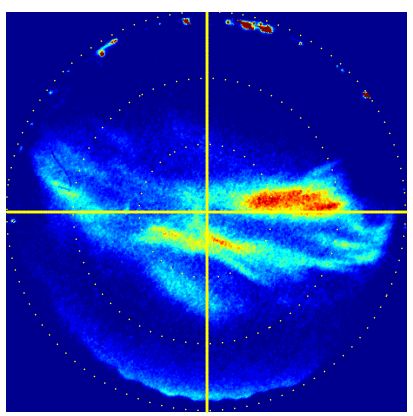

09:52:01

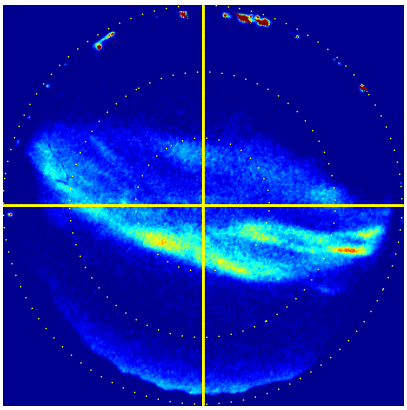

09:57:01

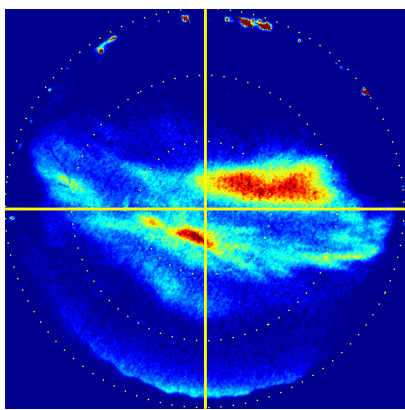

09:54:01

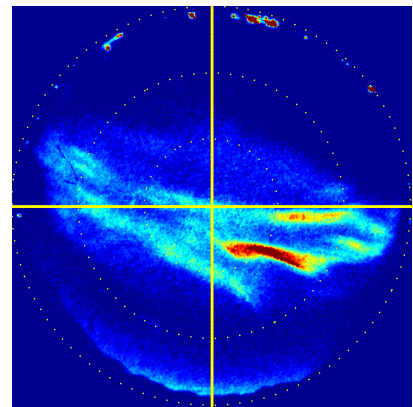

09:58:01

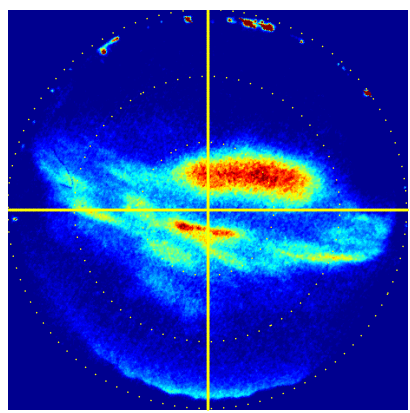

Fig. 5. Ny Ålesund ASC observations at $630.0 \mathrm{~nm}$ for the interval 09:50-09:58 UT on 3 December 1997. The reference frame is zenith angle (dotted circles at 30,60 , and $90^{\circ}$ ) and azimuth. Same format as in Fig. 4. The integration time is $2 \mathrm{~s}$. 
$10: 14: 21$

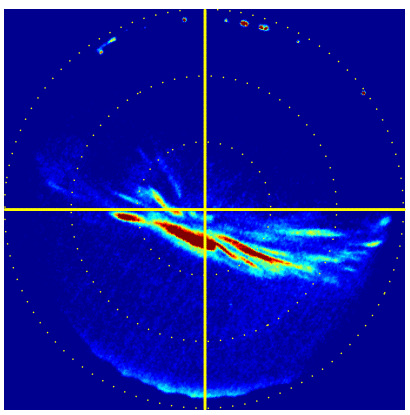

10:17:21

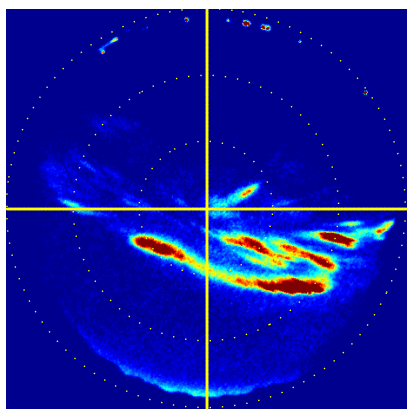

$10: 15: 21$

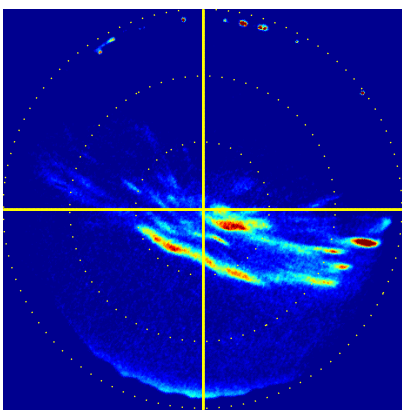

10:18:21

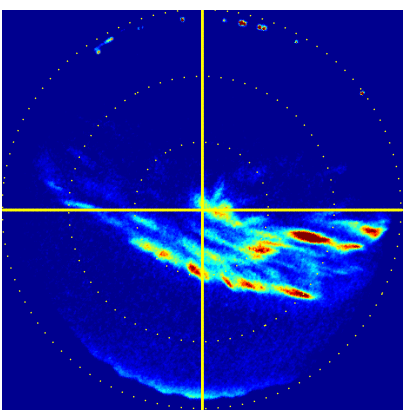

$10: 16: 21$

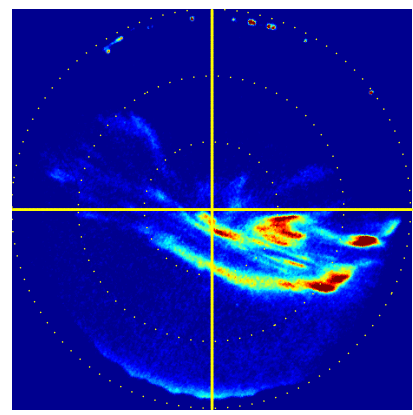

10:19:21

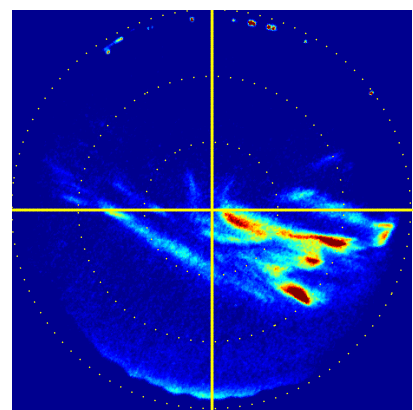

Fig. 6. Ny Ålesund ASC observations at $557.7 \mathrm{~nm}$ for the interval 10:14-10:17 UT on 3 December 1997. The reference frame is zenith angle (dotted circles at 30,60 , and $90^{\circ}$ ) and azimuth. Same format as in Fig. 4. The integration time is $1 \mathrm{~s}$.

$10: 25: 51$

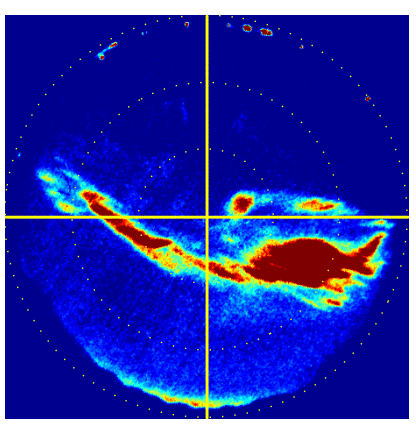

$10: 27: 51$

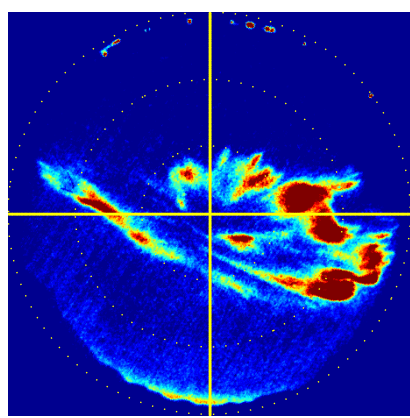

10:29:51

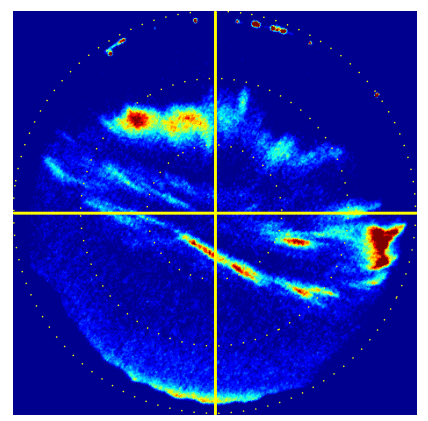

Fig. 7. Ny Ålesund ASC observations at $557.7 \mathrm{~nm}$ for the interval 10:25-10:19 UT on 3 December 1997. Same format as in Fig. 4. The integration time is $1 \mathrm{~s}$.

\subsubsection{Particle precipitation data from DMSP spacecraft}

In Figs. 9 and 10 we show particle precipitation data from spacecraft F11 and F14, obtained during the two intervals when the spacecraft recorded precipitation within the FOV of the ground optical instruments or in its vicinity (see Fig. 2). In Fig. 9 we focus on the interval 10:13-10:17 UT, when spacecraft F11 crossed the optical FOV in the $\sim 11: 00$ 1400 MLT sector. Vertical guidelines along the satellite track in Fig. 2, representing the interval 10:13-10:17 UT, mark transitions between the following particle regimes: mantle (MA)-low-latitude boundary layer (LL)-BPS-void-CPS. The BPS regime is characterized by two narrow layers of electron precipitation at energy $\leq 1 \mathrm{keV}$, centered at 10:15 UT.
This precipitation corresponds to auroral forms marked (a) and (b) in Fig. 2, which, according to the ASC records in Fig. 6, are relatively weaker on the western side of the MSP scanning meridian (near noon), where the satellite intersection ocurred, compared with the eastern side. Just after 10:15 UT, when exiting the region of BPS precipitation/arcs, the satellite instrument recorded an abrupt decrease in the precipitation flux. This is the region we call precipitation void, following the notation of Newell and Meng (1994). At $\sim 10: 15: 40$ UT the spacecraft entered the regime of CPS electrons in the prenoon sector.

Between 10:13-10:15 UT two regions of precipitation (ions and electrons) belonging to the LLBL (LL) and mantle (MA) type were traversed. Both regions show electron fluxes 


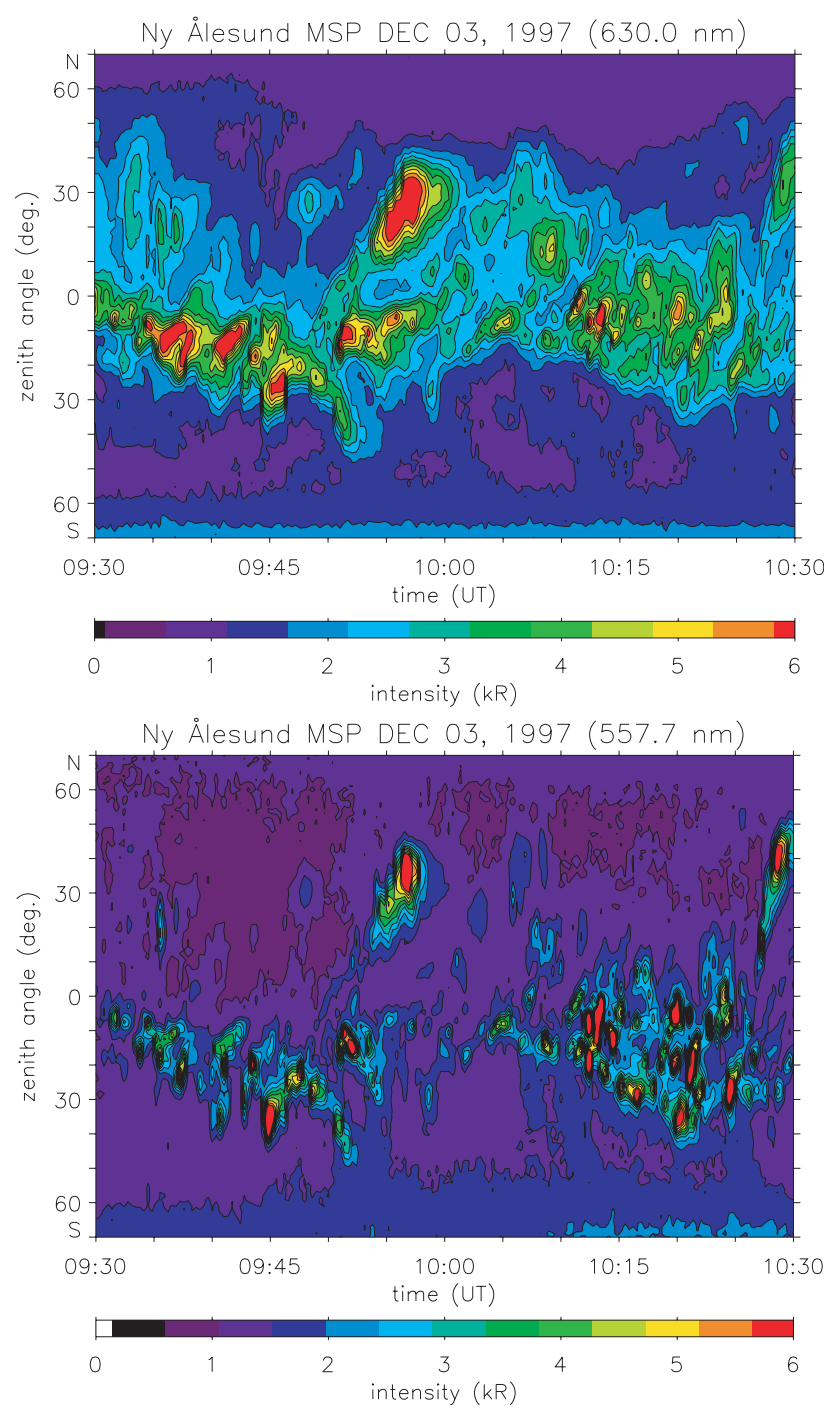

Fig. 8. MSP observations from Ny Ålesund during the interval 09:30-10:30 UT. The upper and lower panels show the red and green line emissions, respectively. Line of sight intensities are color-coded according to the scale the bottom of each panel.

at energy $<300 \mathrm{eV}$ (average energy $\sim 150 \mathrm{eV}$ ) and ion fluxes at energy $<1 \mathrm{keV}$. In the first, highest-latitude patch, the ion energy is $<500 \mathrm{eV}$, while in the later, located at $\sim 76^{\circ}$ MLAT, the ion energy is $\leq 1 \mathrm{keV}$. We note that the cusp-type precipitation recorded at $\sim 77^{\circ}$ MLAT $(\sim 10: 13: 30-10: 14: 00$ UT) corresponds to the aurora located between $\sim 20-30^{\circ} \mathrm{NZ}$ in Fig. 8 (see the observation geometry in Fig. 2). This is the northernmost auroral form recorded by the MSP in Ny Ålesund. The actual aurora, which we label (c), is particularly strong during the intervals 09:55-10:00 UT and 10:2710:30 UT, but is also present at reduced intensity at the time when the satellite crossed the MSP meridian, at 10:13:30 UT (Fig. 8). The particle precipitation observed at this time we classify as mantle.
Then we move to the DMSP F14 data shown in Fig. 10. As an introductory remark we note from Fig. 2 that F14 traversed two closely spaced arcs, which we mark (a) and (b), within the 75-76 ${ }^{\circ}$ MLAT/13:30-15:00 MLT sector during the interval 10:24:30-10:25:30 UT. The particle precipitation data show two "patches" of intense fluxes of keV electrons corresponding to these auroral forms, which are identified in Fig. 7. The precipitation in these two strong arcs are classified as dayside BPS. The energy spectrum of the electron flux, reaching high levels within the range $0.7-4 \mathrm{keV}$, is consistent with the strong intensity of the green line emission ( $\sim 10 \mathrm{kR})$, appearing as bright (red) spots in the lower panel of Fig. 8.

After crossing the southernmost arc labelled (a) in Fig. 2 spacecraft F14 went into a region of markedly reduced particle fluxes in the 13:00-14:00 MLT/74-75 MLAT sector. This is the void regime. Thereafter, it entered a broad zone of CPS electrons. The strong fluxes of discrete electrons recorded in the dusk sector between 10:19-10:22:30 UT we called nightside BPS in Fig. 2.

Figure 11 shows particle precipitation data from the duskdawn pass of spacecraft DMSP F13 during the interval 10:44-11:02 UT. We shall focus on the double-arc traversed within $\sim 14: 00-15: 00 \mathrm{MLT} / 76-77^{\circ}$ MLAT at $\sim 10: 49$ UT. The satellite track is indicated in Fig. 2. The auroral condition at 10:49 UT is very similar to that observed at the time of the F14 pass through the same sector at 10:25 UT. We shall be concerned with the documentation of the particle source of the northernmost postnoon sector auroral form, which we have marked (c). From the present figure we can see that it consists of $\mathrm{keV}$ electrons, and that it is well separated from the oval aurora and the R1 current system (see bottom panel of Fig. 11) on its southern side. Thus, our arc (c) is the same phenomenon as that referred to as polar cap arc (PA) by Lyons et al. $(1996,1999)$. In the present paper we document the morphology and dynamics of this auroral type and we shall be able to place it in the broader context of dayside auroral activity which takes place during magnetopause reconnection events. The electron precipitation is very weak (classed as void) on the poleward side of the polar arc, before the satellite entered into the regime of polar rain precipitation in the central polar cap. The discrete auroral forms corresponding to the precipitation encountered on the prenoon side are those marked (a), (b), and (c) in the schematic Fig. 2.

\subsubsection{Ground magnetic deflections}

$\mathrm{X}$ component magnetic deflections from the Svalbard network of IMAGE magnetometer stations (see http://www.geo. fmi.fi/image/) for the interval 05:00-11:00 UT on 3 December 1997 are shown in Fig. 12. The stations, ordered from north $\left(76^{\circ} \mathrm{MLAT}\right)$ to south $\left(71^{\circ} \mathrm{MLAT}\right)$, are Ny Ålesund (NAL), Longyearbyen (LYR), Hornsund (HOR), Hopen (HOP), and Bear Island (BJN). An interval of quiet conditions (absence of magnetic transients) is observed during 07:50-08:30 UT (11:20-12:00 MLT). A series of positive X 
F11

3 Dec 1997

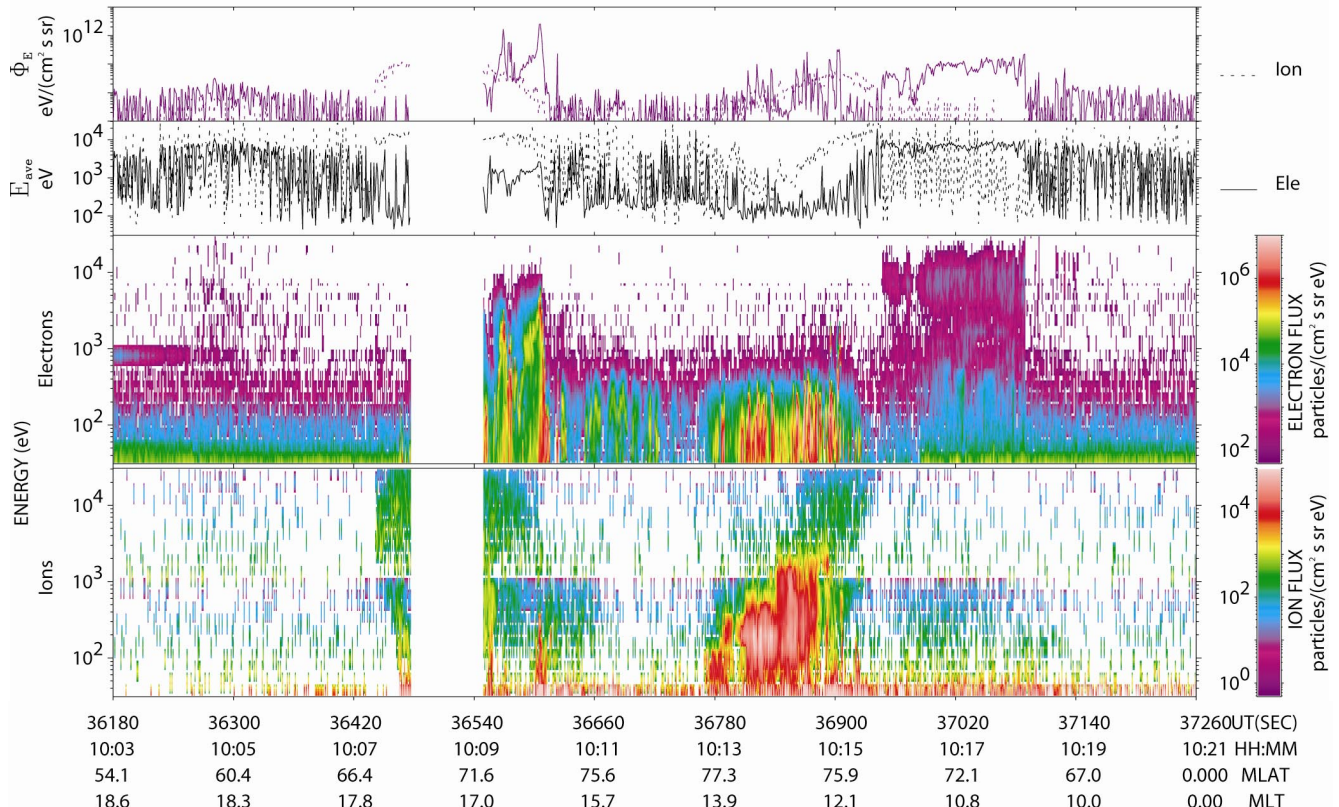

Fig. 9. Particle spectrograms and ionospheric ion drift obtained from spacecraft DMSP F13 during the interval 10:03-10:21 UT on 3 December 1997. Panels 1 and 2 show differential energy flux for electrons (solid) and ions (dashed) and average energy, respectively. Panels 3 and 4 show color-coded particle spectrograms for electrons and ions, respectively. Panel 5 show ion drift in the horizontal (cross track; violet) and vertical (upward; green) directions.

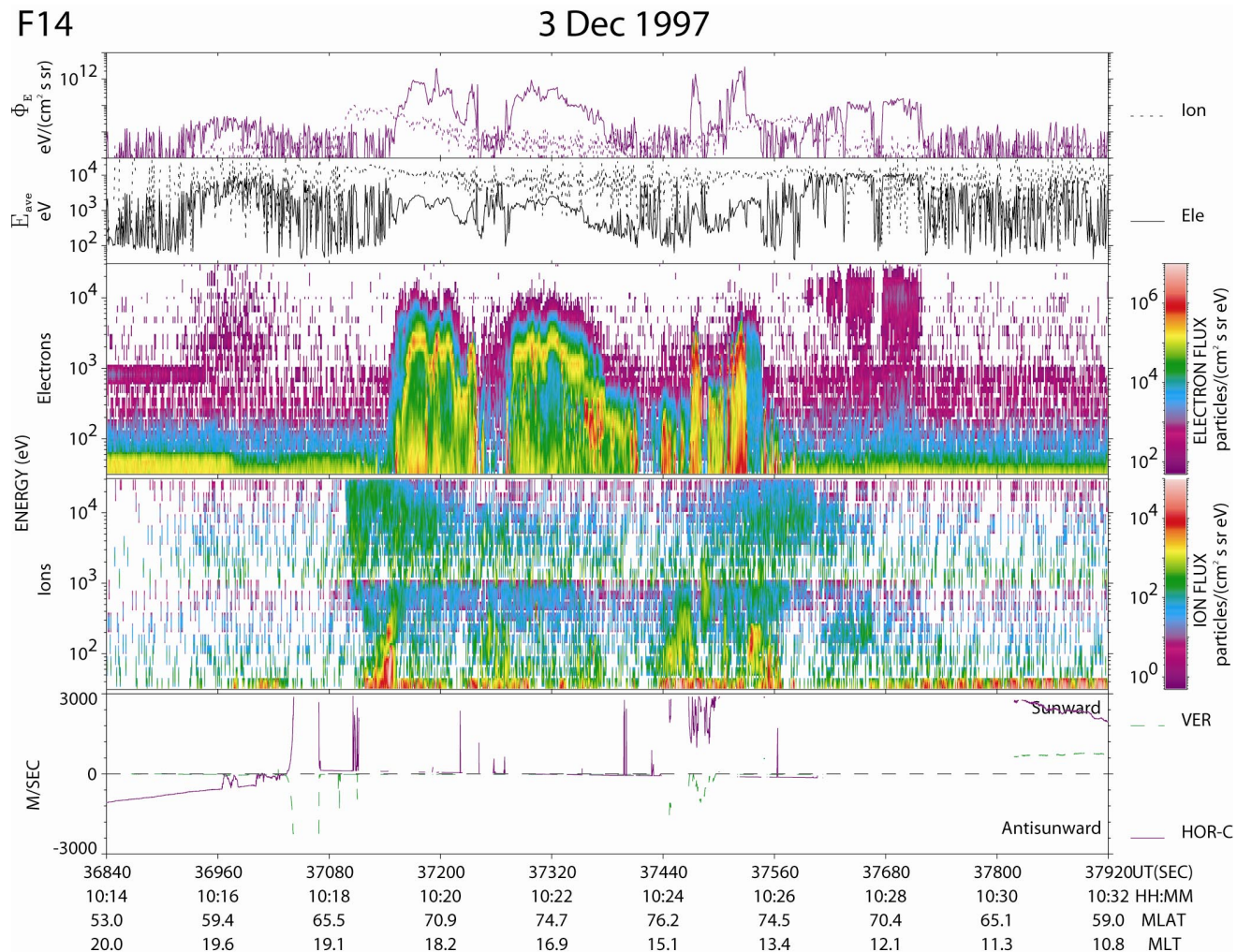

Fig. 10. Particle precipitation obtained from spacecraft F14 during the interval 10:14-10:32 UT on 3 December 1997. Same format as in the previous figure. 
F13 3 Dec 1997

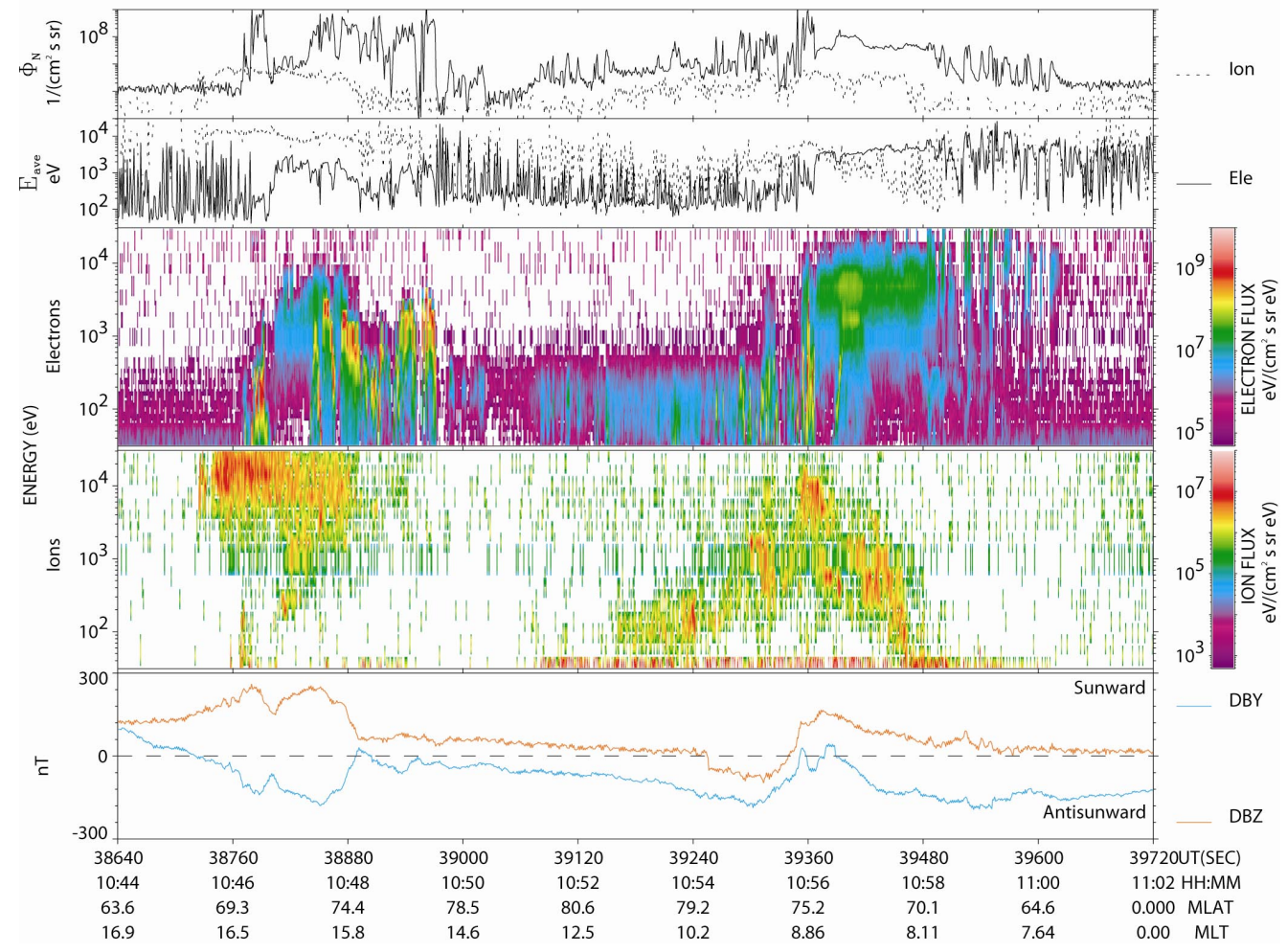

Fig. 11. Particle precipitation and magnetic deflections obtained from spacecraft F13 during the interval 10:44-11:02 UT on 3 December 1997. Same format as in the previous figure except for the bottom panel which shows two components of magnetic deflection: DBY (blue; along the track) and DBZ (red; normal to the track).

deflections occurred both before and after this interval. These magnetic events are associated with auroral brightenings, some of which are reported above, or in previous studies. Among these are: (i) 05:40-06:00 UT (see Farrugia et al. (2003)), (ii) 07:40 UT (Fig. 4), (iii) 08:50 UT (Fig. 3), (iv) 09:50 UT (Fig. 5), and (v) 10:25-10:30 UT (Fig. 7).

A qualitative sketch illustrating essential features of the equivalent convection pattern derived from the IMAGE magnetometers on 3 December 1997 is shown in Fig. 13. Three separate channels of strong westward equivalent convection are marked by broad arrows with hatching. These channels correspond to distinct auroral activities in the corresponding sectors. The magnetic activity is strongly pulsed as is the aurora. The channel of strong X-deflection in the 12:0016:00 MLT sector (marked DP2) is longitudinally separated from a similar, but weaker channel in the 08:00-11:00 MLT sector (no hatching) by a "gap" in the 11:00-12:00 MLT sector. This "gap" corresponds to the quiet interval (07:5008:30 UT) in Fig. 12.

We now turn to the deflection mode labelled DPY1 in Fig. 13, which under the prevailing positive IMF $B_{y}$ conditions is strong in the prenoon sector. This is the SvalgaardMansurov effect (Svalgaard, 1973, 1975). The field-aligned current system and aurorae associated with this magnetic effect on 3 December 1997 have been reported by Farrugia et al. (2003). We note that the poleward boundary of the
DPY1 effect is not known due to the lack of magnetic stations beyond $76^{\circ}$ MLAT. But from ion drift observations obtained during cross polar cap passes by spacecraft DMSP F13 we know that this type of convection channel has a relatively narrow latitudinal extent at the polar cap boundary (see below). The FAC system connected to the flow channel in the present case spans the latitude range $75-80^{\circ}$ MLAT (Farrugia et al., 2003), as indicated in the figure.

Particle precipitation regimes along the DMSP F13 trajectory, obtained during the interval 10:46-11:58 UT on this day (see Fig. 11), are indicated in Fig. 13. We note the following features. In the the midday sector (beyond $80^{\circ}$ MLAT) F13 recorded polar rain precipitation, before traversing a zone of mantle (MA) precipitation within $77-80^{\circ}$ MLAT in the 09:00-11:00 MLT sector. The latter zone, which is typically accompanied by enhanced antisunward convection (speeds within $1-2 \mathrm{~km} / \mathrm{s}$ ), and a corresponding belt of Hall current, is that accounting for the DPY1 magnetic deflection (the Svalgaard-Mansurov effect) marked in Fig. 13.

The northernmost convection channel in the postnoon sector (marked DPY2) corresponds to the auroral form labelled (c) in Fig. 2. In some cases this convection mode (DPY2) is activated while the other (DPY1) is not (see the 09:1509:20 UT event in Fig. 12). This event was triggered by the northward rotation of the IMF recorded by Wind at 08:18 UT (Fig. 1). In other cases both DP channels are present, giving 


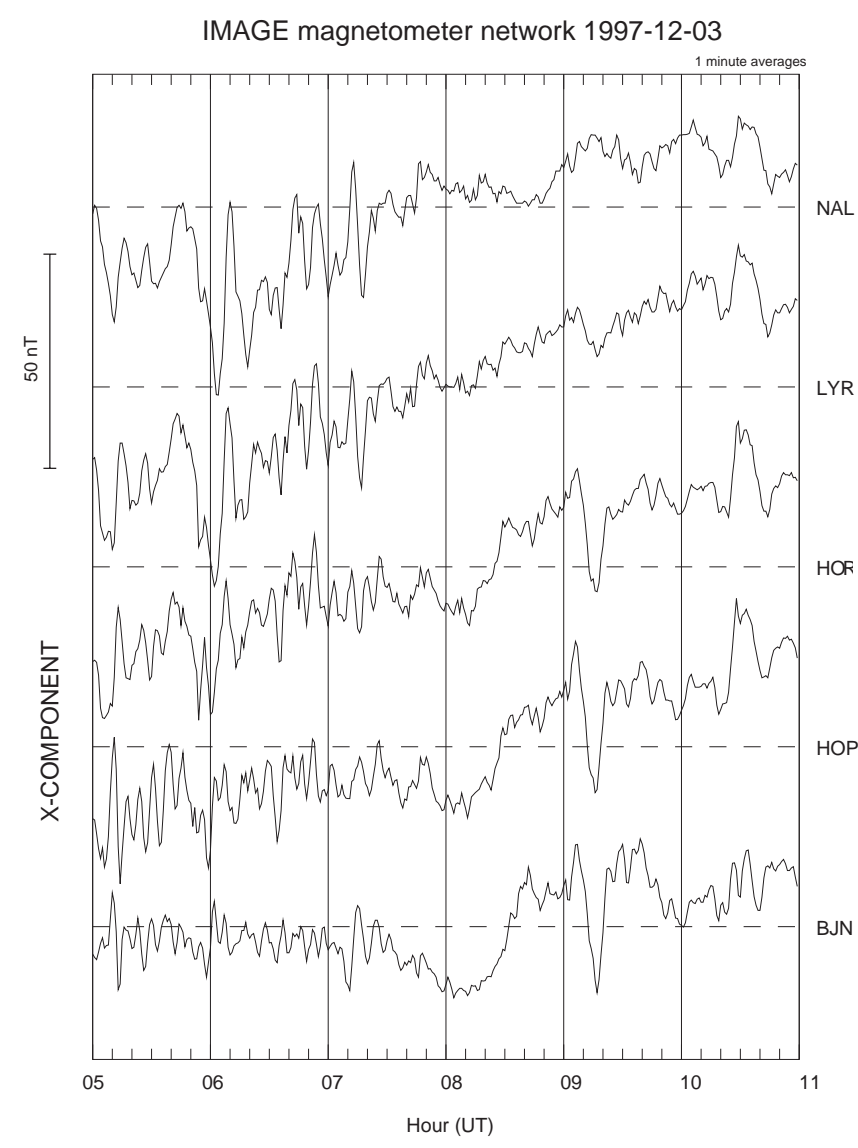

Fig. 12. X component magnetic deflections from the Svalbard IMAGE stations, spanning the latitude range from $76^{\circ}$ MLAT (NAL) to $71^{\circ}$ MLAT (BJN). The interval shown is 05:00-11:00 UT on 3 December 1997.

rise to a very wide latitude range of $\mathrm{X}$ deflection, such as during the 10:25-10:35 UT event on 3 December 1997. In general, DP2 and DPY1 are both activated by southward turnings of the IMF, while DPY2 is activated by northward turnings. The deflection modes DPY1 and 2 are strongly related to the IMF $B_{y}$ polarity. Some of the magnetic deflections belong to the category of Pc 5 pulsations, which is typical for the closed field line regime in the prenoon sector (see stations HOR-HOP-BJN during the interval 05:00-07:30 UT on 3 December 1997).

\subsection{Case 2: 12 December 1999}

Although the IMF orientation on 3 December 1997 (case 1) was rather stable and characterized by $B_{y}>0$ and $B_{z}<0$, some variability is observed, which is not ideal in relation to our purpose of distinguishing between temporal and spatial structure in the dayside aurora. In an attempt to remove this possible source of ambiguity we searched in our database for a day with similar IMF orientation $\left(B_{y}>0 ; B_{z}<0\right)$, but even more stable conditions than in case 1 . We found an almost perfect day in this respect: 12 December 1999.

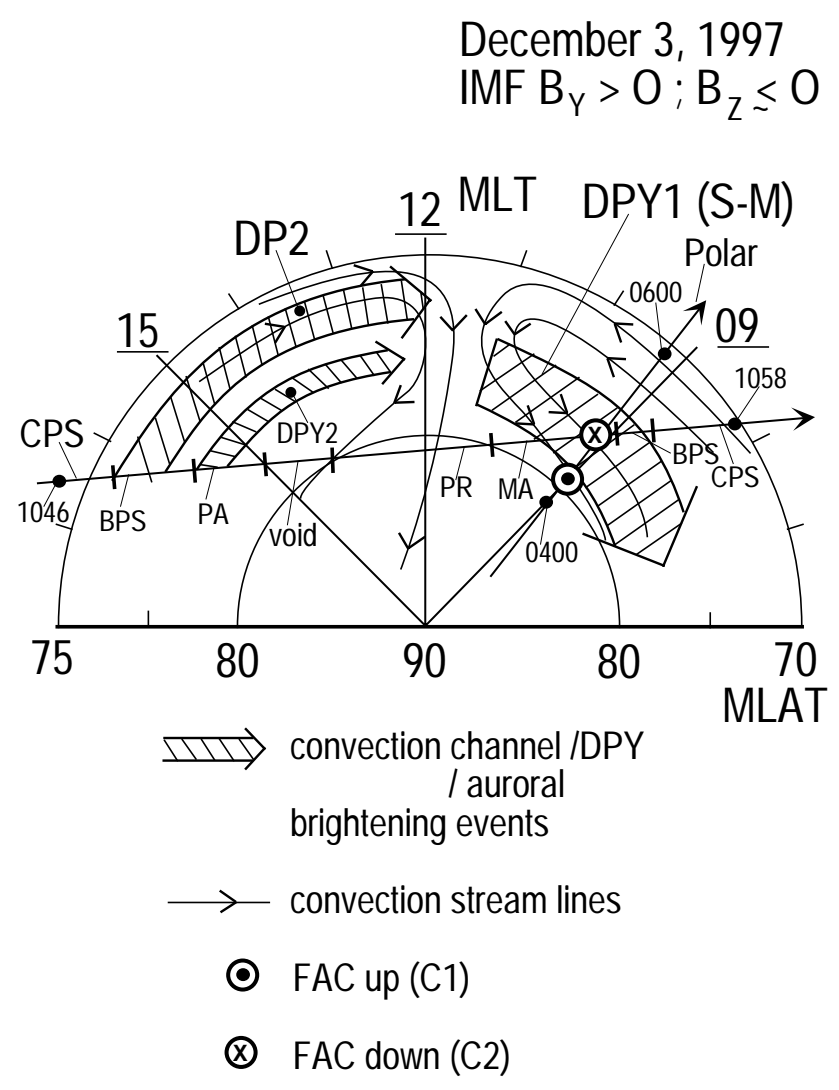

Fig. 13. Schematic illustration of equivalent convection in MLAT/MLT coordinates for IMF $B_{z}<0 ; B_{y}>0$ conditions, as derived from the IMAGE chain $\mathrm{X}$ component magnetic deflections on 3 December 1997. Three regions of strong magnetic deflection are marked by arrows with hatching. They are labelled DP2 (strongest effect seen in the postnoon sector), DPY1 (the SvalgardMansurov effect; strongest in the prenoon sector), and DPY2 (postnoon sector). Trajectories of spacecraft DMSP F13 during the interval 10:46-10:58 UT and Polar during the interval 04:00-06:00 UT are indicated.

\subsubsection{IMF and solar wind plasma data}

Figure 14 shows solar wind plasma and IMF observations obtained from spacecraft Wind during the interval 05:00 12:00 UT on 12 December 1999. The positions of Wind at $05: 00$ and $12: 00 \mathrm{UT}$ are $(-16.0 ;-58.6 ; 15.1) R_{E}$ and $(-13.8 ;-57.3 ; 15.8) R_{E}$, respectively. We can see that the solar wind and IMF conditions are exceptionally stable during this 7-h long interval. We note the following features: (i) solar wind speed at $350-400 \mathrm{~km} / \mathrm{s}$, (ii) solar wind dynamic pressure at $0.1-0.2 \mathrm{nPa}$ (well below the average value), (iii) $B_{x}<0 ; B_{y}>0$ (3 nT); $B_{z}<0(-1,-3 \mathrm{nT})$, (iv) IMF clock angle generally within the range $120-150^{\circ}$. Below we will report on the spatial-temporal structure of the dayside aurora under this condition, obtained from the ground as the station rotated with the Earth through the prenoon and midday sectors during the interval 06:00-10:00 UT. 


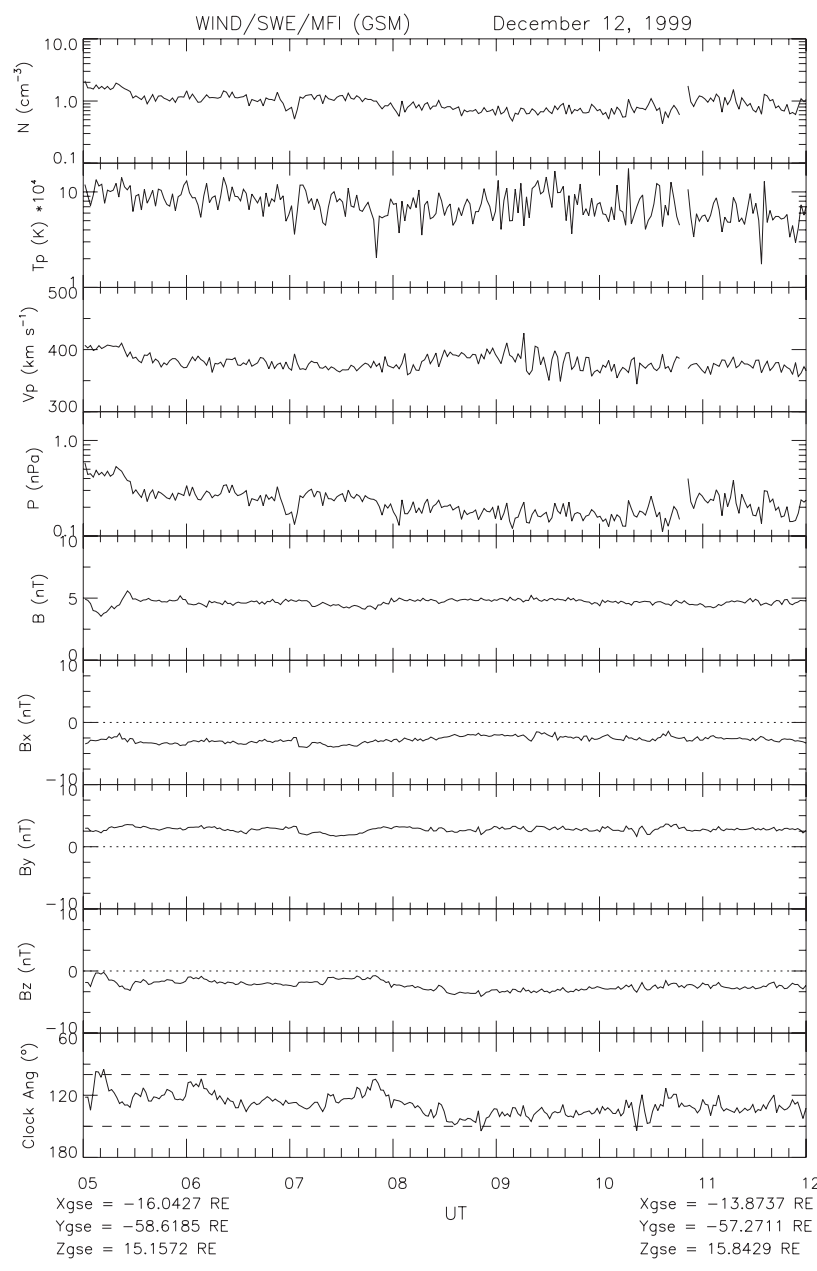

Fig. 14. Solar wind plasma and IMF observations from spacecraft Wind during the interval 05:00-12:00 UT on 12 December 1999. Panels from top to bottom shows proton density, bulk speed, temperature, solar wind dynamic pressure, the total field intensity and the GSM components $\left(B_{x}, B_{y}\right.$, and $\left.B_{z}\right)$ of the interplanetary magnetic field (IMF), and the clock angle in the GSM Y-Z plane.

\subsubsection{Overview of aurora and polar cap convection}

Figure 15 shows a schematic overview of essential features of the dayside aurora on 12 December 1999 as derived from the ground perspective in Ny Ålesund. ASC fields of view corresponding to two representative intervals of the auroral activities in the prenoon and midday/postnoon sectors, repectively, are marked A and B in the figure. The actual time intervals are 07:10-07:30 UT (A), and 09:10-09:25 UT (B). Perspective A shows three latitudinally separated forms in the prenoon sector, labelled (a), (b), and (c). As we shall demonstrate below, these forms are sequentially activated (progressing from lower to higher latitudes) during brightening events. Auroral motions are indicated by arrows. The auroral brightenings in the postnoon sector (AB east) typically expand westward and poleward (marked by arrow) before fading (marked by dashed line) in the vicinity of the zenith of the station or even further north. A feature to notice

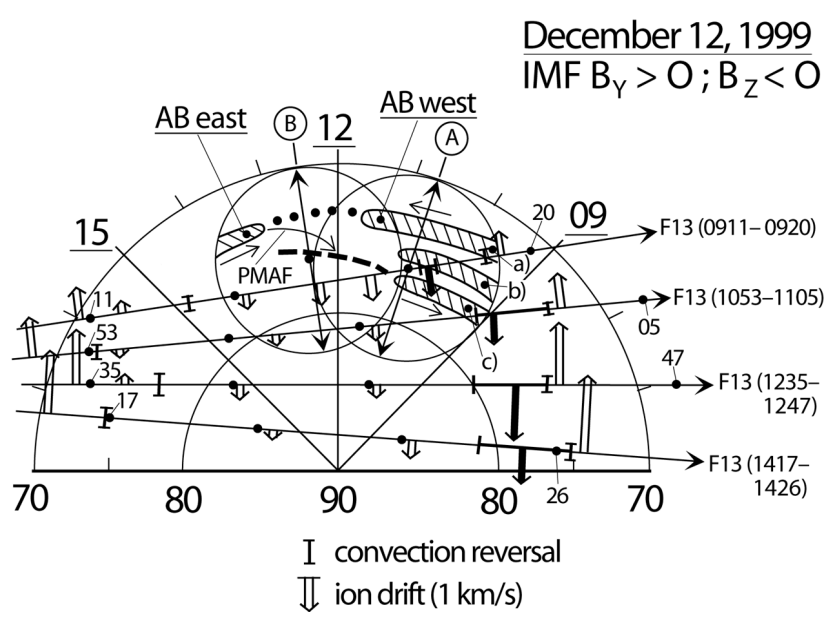

Fig. 15. Schematic illustration of the dayside auroral configuration in the 09:00-14:00 MLT sector, applicable to the interval 07:00-10:00 UT on 12 December 1999, and polar cap convection derived from four DMSP F13 passes during the interval 09:10 14:30 UT. The coordinate system is MLAT/MLT. The fields of view at $630.0 \mathrm{~nm}$ of the MSP and all-sky camera (ASC) in Ny Ålesund for 07:20 UT (A), and 09:15 UT (B), are marked by double-arrowed meridional lines and circle, respectively. Track of DMSP spacecraft F13 during the intervals 09:11-09:20, 10:53-11:05, 12:35-12:47, and 14:17-14:26 UT are indicated. Horizontal cross-track ion drifts are marked along the tracks. Hatched areas represent the location of auroral forms. Midday gap aurora is indicated by dotted line.

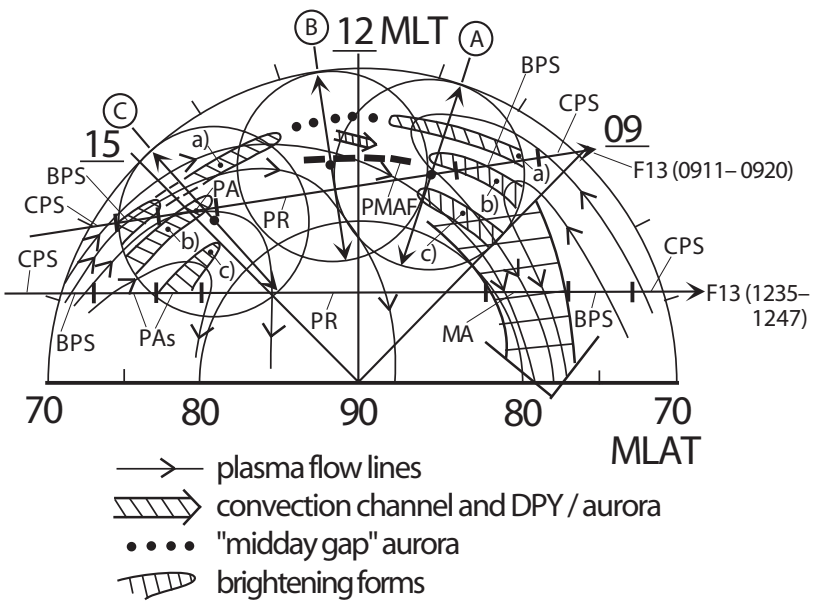

Fig. 16. Schematic illustration of auroral observations in relation to plasma convection for 12 December 1999 (case 2) in MLT/MLAT coordinates. Auroral forms appearing within the FOV of the optical instruments in Ny Ålesund are shown by hatching for the following intervals: 07:10-07:30 UT (A), 09:10-09:30 UT (B), and 11:1011:30 UT (C). Convection channel on the dawn side of the polar cap is marked by broad arrow. Particle precipitation regimes along two DMSP F13 tracks are indicated.

is that the two separate brightenings ( $\mathrm{AB}$ west and $\mathrm{AB}$ east) appear to occur near-simultaneously (within $1 \mathrm{~min}$ ). 

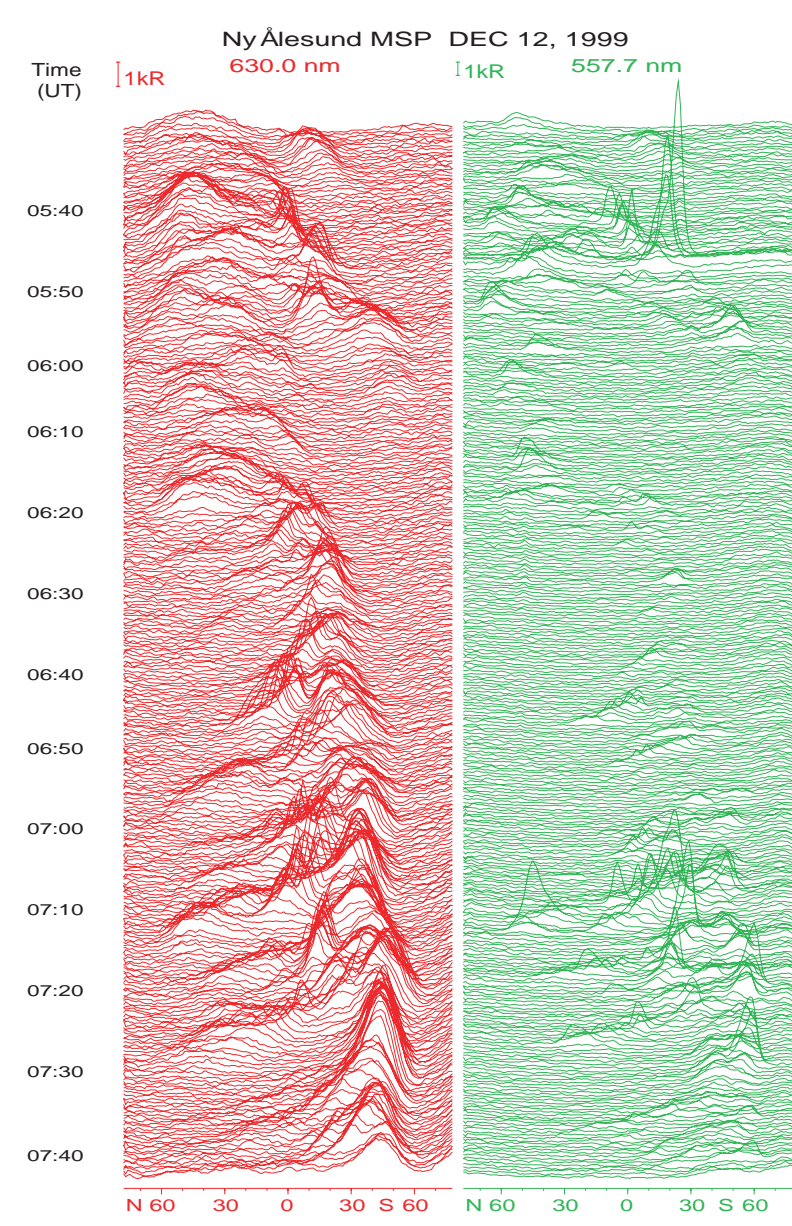

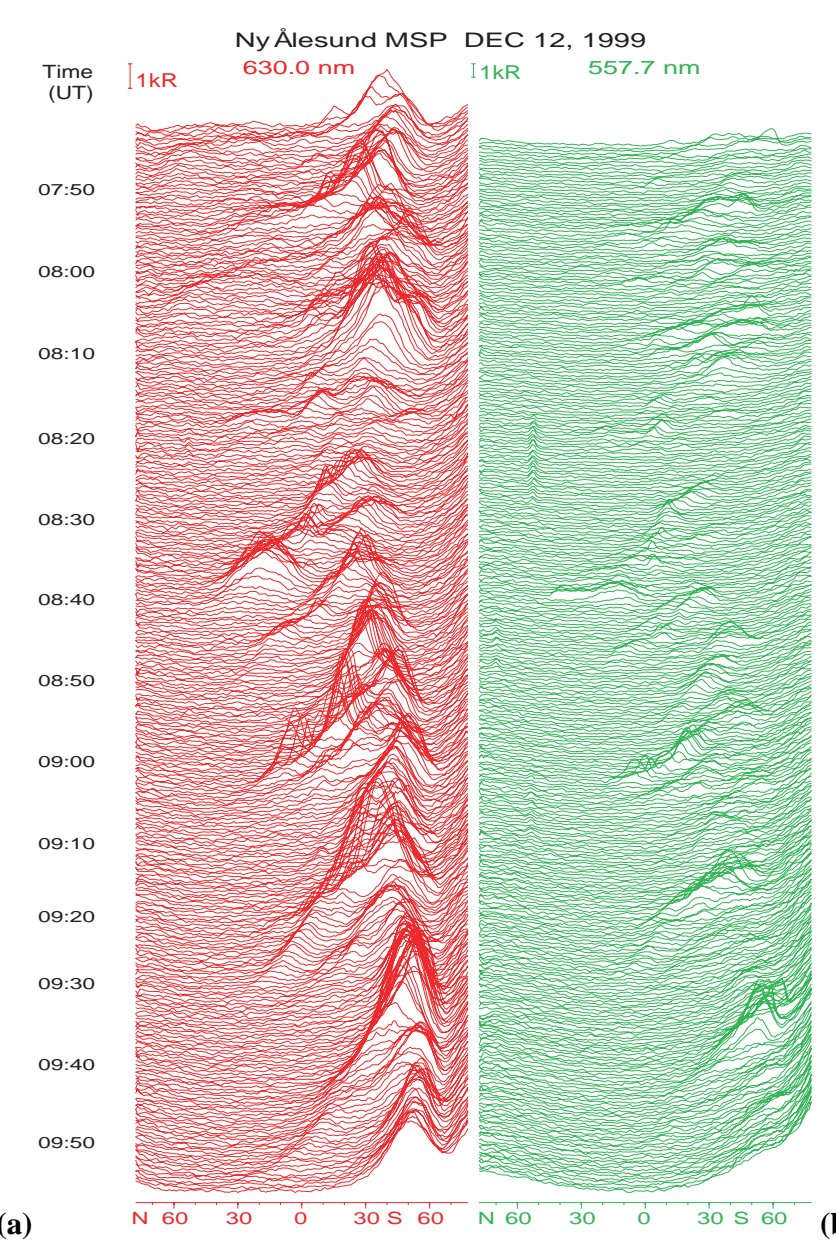

Fig. 17. MSP observations from Ny Ålesund during the intervals (a) 05:30-07:40 UT and (b) 07:40-09:55 UT. Left and right columns show stacked plots of line of sight intensity vs. zenith angle for the wavelength channels at 630.0 and $557.7 \mathrm{~nm}$, respectively. Same format as in Fig. 3.

The figure also shows cross track ionospheric ion drift obtained from four successive DMSP passes across the polar cap on 12 December 1999. These observations are included in order to place the auroral observations in the context of polar cap convection. We place focus on the presence of a $5^{\circ}$-wide convection channel in the prenoon sector (06:0009:00 MLT/75-80 MLAT) of the polar cap. A rather homogeneous convection, directed antisunward at moderate speed $(\leq 0.5 \mathrm{~km} / \mathrm{s})$, is observed in the center of the polar cap (above $80^{\circ}$ MLAT), where the particle precipitation is of type polar rain. A much higher $(1-2 \mathrm{~km} / \mathrm{s})$ antisunward ion drift is observed within the sector 75-80 $0^{\circ}$ MLAT/07:00-09:00 MLT. Thus, we refer to this as a convection channel. It is marked in the figure by bars along the track (the latitudinal extent) and thick arrows (representing the flow speed component normal to the track). Similar ion drift speeds $(2 \mathrm{~km} / \mathrm{s})$ in the opposite direction (sunward) are observed equatorward of the sharp convection reversal boundary. The convection reversals are marked along each satellite pass. The reversal during the earliest pass (closest to noon; at 09:45 MLT; $73^{\circ}$ MLAT) is rather gradual, showing the character of a rotational rever- sal, while the others (within the 06:00-09:00 MLT sector) are very sharp, indicating a shear reversal. As we shall see below, the channel of strong antisunward convection in the dawn-prenoon sector of the polar cap gives rise to a characteristic mode of ground magnetic deflection, often referred to as DPY, or the Svalgaard-Mansurov effect. We note that the convection channel in the 09:00-11:00 MLT sector is observed to be colocated with the strong auroral forms labelled (b) and (c).

A summary of the association between features of the dayside auroral structure and plasma convection/DPY magnetic deflection in the polar cap (DMSP F13 ion drift data and ground magnetograms) for 12 December 1999 (case 2) is given in Fig. 16 which shows auroral forms within the 09:00-16:00 MLT sector by a combination of fields of view representing the time intervals 07:10-07:30 UT (A), 09:1009:30 UT (B), and 11:10-11:30 UT (C). Plasma flow lines are drawn on the basis of ion drift data obtained from the four cross polar cap passes of DMSP F13 shown in Fig. 15. The aurora representing 11:10-11:30 UT (marked C in the figure) is included here for completeness, but is not described 
08:26:00

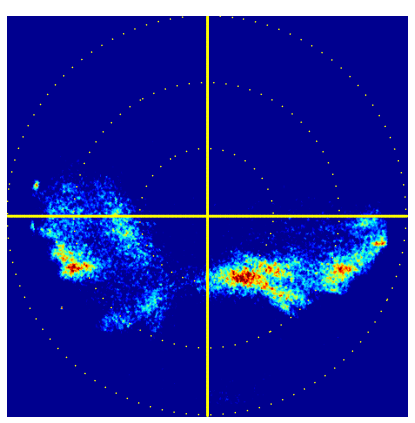

08:32:00

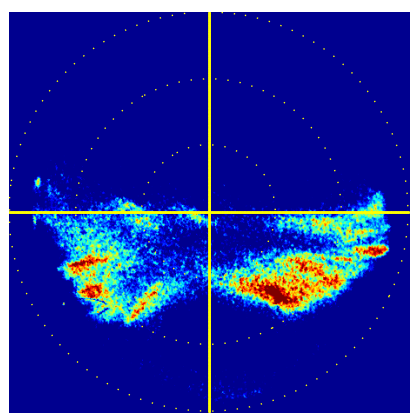

08:28:00

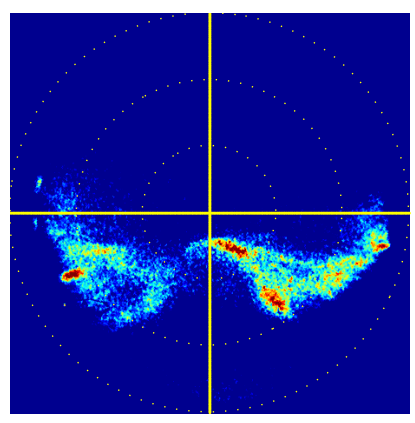

08:34:00

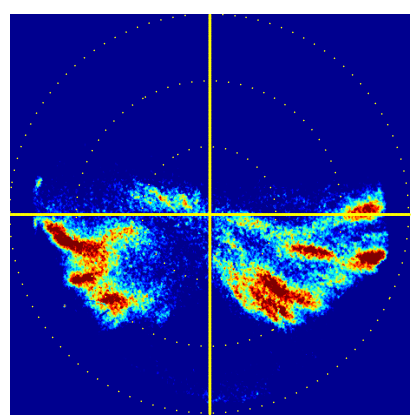

08:30:00

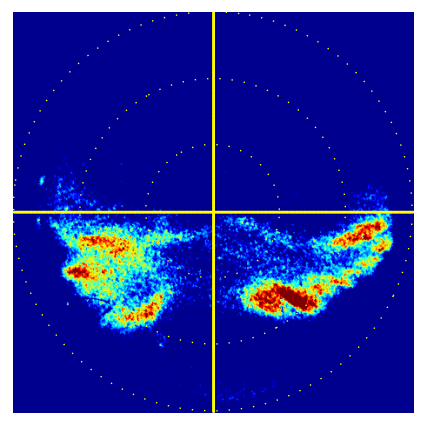

08:36:00

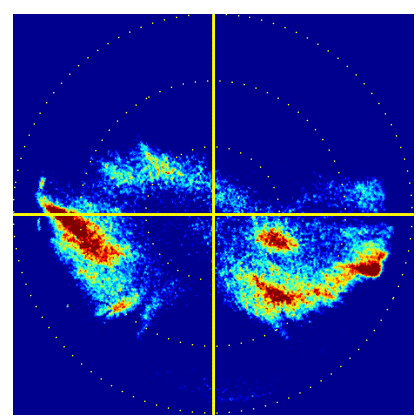

Fig. 18. Ny Ålesund ASC observations at $630.0 \mathrm{~nm}$ for the interval 08:26-08:36 UT on 12 December 1999. The reference frame is zenith angle (dotted circles at 30,60 , and $90^{\circ}$ ) and azimuth. Same format as in Fig. 4. The integration time is $2 \mathrm{~s}$.

in detail in this paper. Auroral forms located at different latitudes in the pre- and postnoon sectors are labelled (a), (b) and (c). The following particle precipitation zones are marked along two DMSP F13 tracks: CPS (central plasma sheet), BPS (boundary plasma sheet), PAs (polar cap arcs), PR (polar rain), MA (mantle), BPS, and CPS. The detailed particle precipitation and ion drift data for these two F13 passes are shown in the next chapter. Equivalent convection in regions of DPY magnetic deflections are marked by hatching and arrows. The 12:00-13:00 MLT sector is characterized by classical poleward moving auroral forms (PMAFs) and associated DPY magnetic transients, while sequential activations of latitudinally separated forms (those marked (a), (b), and (c) and a broad convection channel (and associated DPY deflection) within $75-80^{\circ}$ MLAT are prominent features in the prenoon sector.

\subsubsection{Auroral observations in detail}

Figures 17a and b show Ny Ålesund MSP observations for the intervals 05:30-07:40 and 07:40-09:55 UT, respectively. During the interval 05:30-10:00 UT the ground station swept through the sector 09:00-13:30 MLT. Early on (05:30-06:20 UT) we find the aurora located mainly to the north of zenith (within $0-60^{\circ} \mathrm{NZ}$ ). The northernmost form is the prenoon sector form marked (c) in Fig. 16. A strong auroral form (type (a) in Fig. 16) is present in the vicinity of zenith during 05:40-05:50 UT. Then a brightening in the vicinity of zenith at 06:20 UT is followed by a sequence of similar brightening events. The auroral equatorward boundary is migrating equatorward until 07:20 UT.

Particularly strong auroral events, also in the green line, are observed during the interval 07:05-07:30 UT. This auroral activity appears in the form of sequential activations of the latitudinally separated forms marked (a), (b), and (c) in the schematic Fig. 16. We emphasize that the northernmost aurora observed in the prenoon sector (see MSP interval 05:40-07:30 UT) is that referred to as form (c) in the schematic Fig. 16.

The aurora in the MSP meridian plane is particularly weak during the interval 08:10-08:30 UT (11:4012:00 MLT). Then a sequence of seven classical brightening events/poleward moving auroral forms (PMAFs) is seen between 08:30 and 10:00 UT. Thus, the average recurrence time is $13 \mathrm{~min}$. The 2-D evolution of these events is indicated in the schematic Fig. 15. As an illustration of the 2-D aurora around the time of the minimum MSP intensity recorded around 08:20-08:30 UT we shall apply the all-sky camera (ASC) sequence shown below.

Figure 18 shows $\mathrm{Ny}$ Ålesund ASC observations at $630.0 \mathrm{~nm}$ for the interval 08:26-08:36 UT. The first image (0826 UT; upper left) shows the very beginning of a brightening event. Brightenings in the eastern and western parts of the FOV (slightly south of the station) are separated by a clear "gap" centered slightly to the south-east of the station. The brightening saturates at around 08:34 UT (lower middle). At this time a poleward moving auroral form (PMAF) is seen to advance northwestward, beyond the zenith. 
$\underline{0830 \text { UT }}$

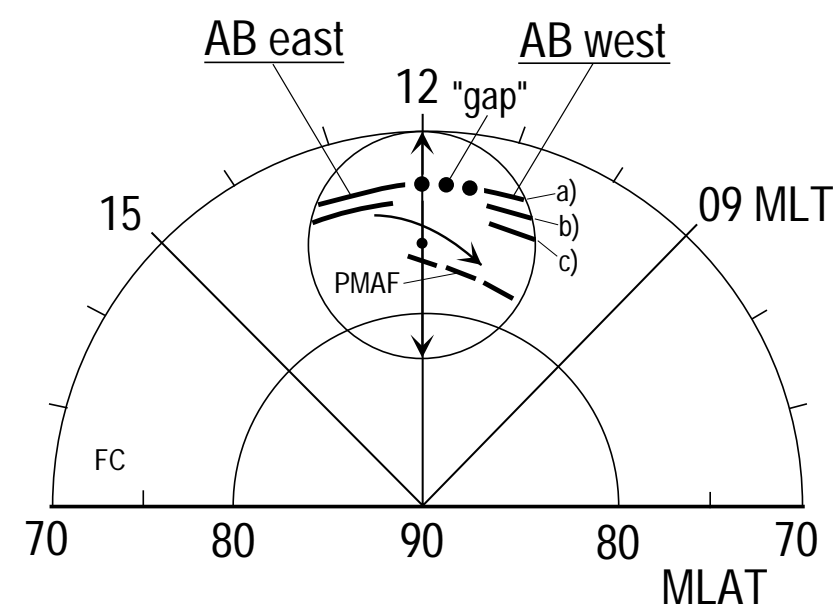

Fig. 19. Schematic illustration of the auroral brightening event during the interval 08:25-08:40 UT on 12 December 1999. The coordinate system is MLAT/MLT. Same format as in Fig. 15.

Figure 19 shows a schematic illustration of the aurora within the FOV of the Ny Ålesund ASC during the interval 08:25-08:40 UT. The coordinate system is MLAT/MLT. The auroral event is characterized by the following features: (i) the presence of a midday gap aurora in the 11:3012:00 MLT sector (marked by dots), separating strong auroral forms to the east (postnoon) and west (prenoon), (ii) nearsimultaneous auroral brightenings in the eastern (postnoon) and western (prenoon) parts of the field of view (called $A B$ east and $\mathrm{AB}$ west), followed by (iii) westward and poleward expansions of a form emanating from the $\mathrm{AB}$ east activity. The latter auroral motion is marked by arrow.

As an illustration of the simultaneous nature of the $A B$ east and $A B$ west brightenings, indicated in Figs. 15 and 19, we show in Fig. 20 an ASC sequence for the interval 09:1009:13 UT. The first image (upper left; 09:10:30) shows a weak band stretching across the FOV from east to west to the south of the station. The appearance of spots of higher luminosity is seen at the boundary of the FOV in the east and west at 09:11:00 UT (second image). In the following images the spots grow in intensity. These are the postnoon and prenoon brightenings called $\mathrm{AB}$ east and $\mathrm{AB}$ west in the schematic illustrations. In the last image (lower right; 09:13:30) the two bright spots are well-developed and still separated by a stable band of much weaker emission, the midday gap aurora. Later on the brightening called $\mathrm{AB}$ east (to the right in the image) expanded westward and poleward, as indicated in Figs. 15 and 19. A sharp onset of the brightening is seen in the MSP records when this form (PMAF) entered the MSP field of view at 09:16 UT (see Fig. 17b). This form faded out during the interval 09:25-09:30 UT, 15-20 min after its initial brightening.
2.2.4 DMSP data: particle precipitation and ion drift

Figure 21 shows electron and ion precipitation data and cross-track ion drift obtained at the time of the DMSP pass during 09:07-09:25 UT. The track is indicated in Figs. 15 and 16. Figure 22 shows electron and ion precipitation data and cross track ion drift obtained during the DMSP pass that took place in the interval 12:35-12:47 UT. The track is indicated in Figs 15 and 16.

From these observations we note the following features: (i) Particle precipitation zones traversed along the track from the dusk side to dawn side, as labelled in Fig. 16 are: CPS (central plasma sheet)-BPS (boundary plasma sheet)PA (polar arc)-PR (polar rain)-MA (mantle)-BPS-CPS; (ii) Plasma convection characteristics: (a) central polar cap: homogeneous antisunward flow at typical speeds of 0.6 (09:14 09:18 UT) and $0.4 \mathrm{~km} / \mathrm{s}$ (12:37-12:43 UT), accompanied by polar rain precipitation, (b) channel of strong antisunward convection at speeds of $0.5-1.8 \mathrm{~km} / \mathrm{s}$ at the polar cap boundary $\left(75-80^{\circ}\right.$ MLAT) in the 07:00-08:00 MLT sector (second pass in Fig. 16), accompanied by structured electron precipitation of mantle type, (c) weak (stagnant) flow (cross-track component) at the dusk side of the polar cap, (d) rotational and shear convection reversals on the dawn side, at 10:00 and 07:00 MLT, respectively, and (e) rotational type reversals on the dusk side, both in the 15:00 and 17:00 MLT sectors.

\subsubsection{Ground magnetic deflections}

Figure 23 shows X component magnetograms from the Svalbard IMAGE chain for the interval 05:00-10:00 UT on 12 December 1999. The observed magnetic deflections are studied with reference to the schematic Fig. 16. The positive deflections recorded at the highest latitude stations (maximizing at NAL) from 06:20 UT onwards are clear signatures of the DPY mode (the Svalgaard-Mansurov effect). This activity is related to the strong convection channel and auroral precipitation (auroral form (c)) observed at the polar cap boundary in the prenoon sector, as illustrated in Fig. 16. The magnetic transients observed during the interval 07:10 07:30 UT are events corresponding to the sequential activations of the auroral forms marked (a), (b), and (c) in the schematic figure (see the aurora in Fig. 17a). This is followed by an interval of little X deflection (07:35-08:00 UT). Then a new regime of positive deflection, maximizing at station HOR (74 MLAT), is occurring during 08:00-09:00 UT. Two transient events (positive $\mathrm{X}$ deflections maximizing at HOR-LYR) with clear correspondence to auroral brightenings/PMAFs are observed during the intervals 09:10-09:25 and 09:35-09:50 UT. The equivalent convection associated with these classical poleward moving events, originating in the postnoon sector, are marked in Fig. 16 by the hatched arrow in the 12:00-13:00 MLT sector. 


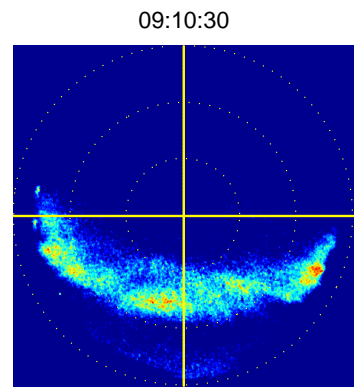

09:12:00

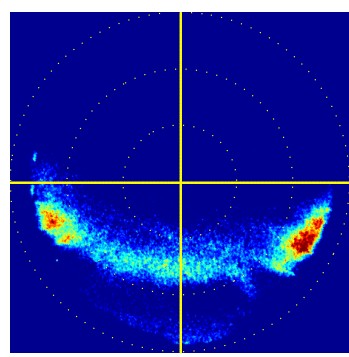

09:11:00

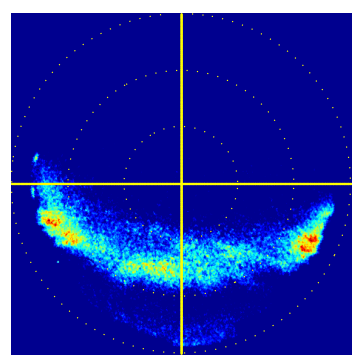

09:12:30

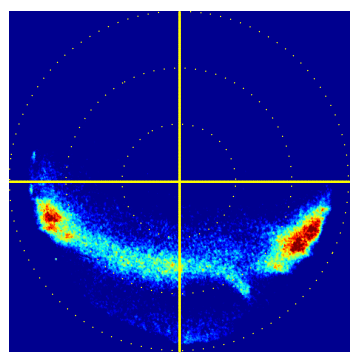

09:11:30

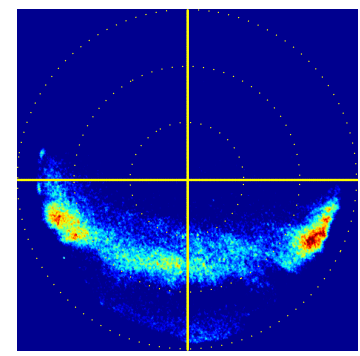

09:13:30

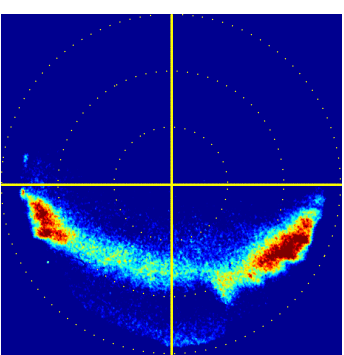

Fig. 20. Ny Ålesund ASC observations at $630.0 \mathrm{~nm}$ for the interval 09:10-09:13 UT on 12 December 1999. Same format as in Fig. 4. The integration time is $2 \mathrm{~s}$.

F13

12 Dec 1999

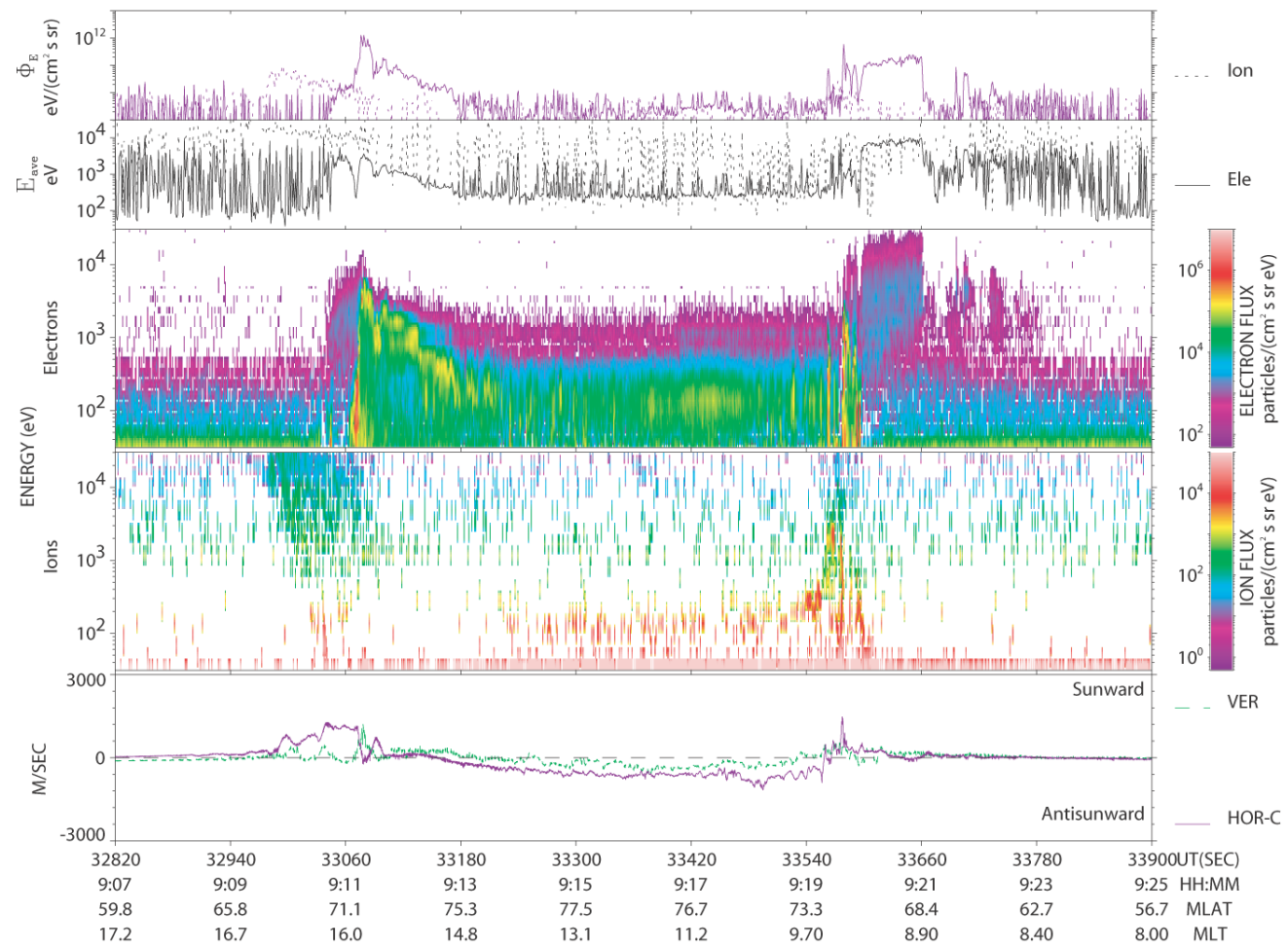

Fig. 21. Particle spectrograms and ionospheric ion drift obtained from spacecraft DMSP F13 during the interval 09:07-09:25 UT on 12 December 1999. Panels 1 and 2 show differential energy flux for electrons (solid) and ions (dashed) and average energy, respectively. Panels 3 and 4 show color coded particle-spectrograms for electrons and ions, respectively. Panel 5 show ion drift in the horizontal (cross track; violet) and vertical (upward; green) directions. 


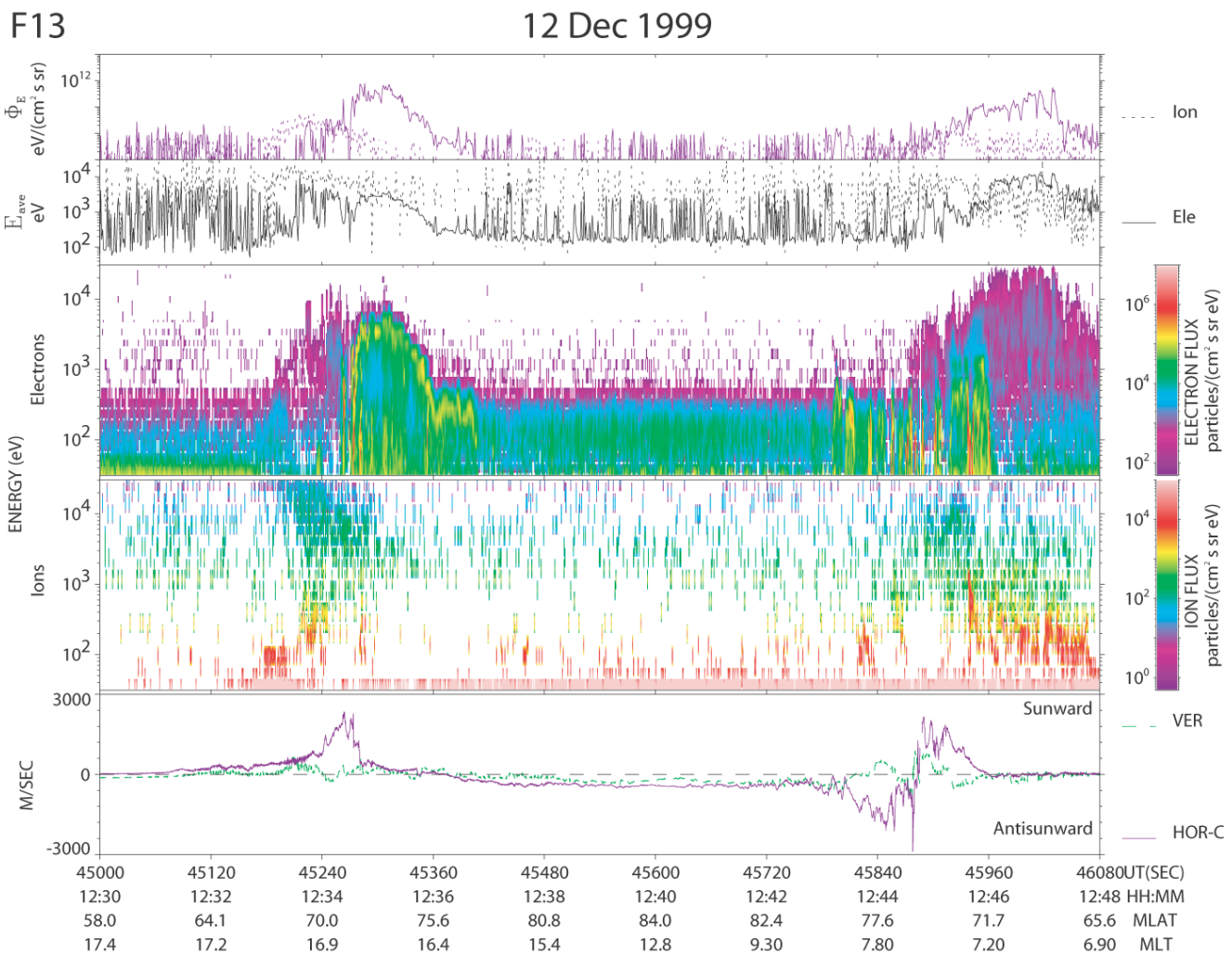

Fig. 22. Particle spectrograms and cross-track ionospheric ion drift obtained from DMSP F13 during the interval 12:30-12:46 UT on 12 December 1999. Same format as in Fig. 21

\section{Summary of observations}

The necessary spatial resolution needed to reveal the true spatio-temporal structure of the dayside aurora can only be obtained by ground-based observations. The limitation due to the restricted FOV can be mitigated by combining the spatial perspectives provided by single ground instruments when they rotate with the Earth during the day. This technique is particularly relevant for cases when the interplanetary magnetic field and solar wind dynamic pressure remain fairly steady over extended intervals, allowing a sampling of auro$\mathrm{ral} /$ ionospheric conditions as a function of MLT. When this technique is applied, synoptic views of the dayside aurora, such as that given in Figs. 2 and 16, are obtained. These figures represent the dayside auroral morphology during IMF $B_{z}<0$ and $B_{y}>0$ conditions. The focus in this study is placed on the spatial structure, in longitude and latitude, of the aurora and its associated plasma convection/magnetic deflection signatures and particle precipitation.

Outstanding features of the observations, as inferred from both cases, are summarized in the schematic Fig. 24 and listed below:

(I) Longitudinal auroral structure:

It is characterized by active auroral forms (BPS precipitation) in the prenoon (08:00-11:00 MLT) and postnoon (12:0016:00 MLT) sectors, separated by a $\sim 1 \mathrm{~h}$ long-interval characterized by a deep minimum in auroral intensity/activity (midday gap aurora) somewhere in the 11:00-13:00 MLT sector. We document that activations of the pre- and postnoon sector forms (called $\mathrm{AB}$ west and $\mathrm{AB}$ east) occur nearsimultaneously (within $1 \mathrm{~min}$ ) in response to magnetopause reconnection events (see also Sandholt et al., 2004; Sandholt and Farrugia, 2003).

(II) Latitudinal auroral structure:

(i) The postnoon activity, consisting of multiple, latitudinally closely separated forms (labelled a, b and c) moving noonwards, are located on sunward convecting field lines. The highest-latitude form (cross-hatched in Figure 24) is related to a convection reversal, possibly associated with a lobe cell, as indicated in Fig. 16. (ii) The activity in the prenoon sector (08:00-11:00 MLT) also consists of latitudinally separated forms which we label (A), (B), and (C) (Fig. 24). These auroral forms span a latitude regime characterized by a staircase type ion dispersion signature (see F13 data in Fig. 11). (iii) While prenoon form $\mathbf{A}$ is located in the regime of sunward convection, form (B) appears close to a rotational convection reversal. (iv) The highest latitude form $(\mathrm{C})$ is associated with a channel of strong antisunward convection, where mantle type precipitation is observed. This aurora appears in the form of a sequence of brightening events well north of zenith of our station in Ny Ålesund (see the interval 05:30-06:20 UT in Fig. 17 a). The high-altitude plasma injections and FACs (observations from spacecraft Polar) associated with this type of auroral activ- 


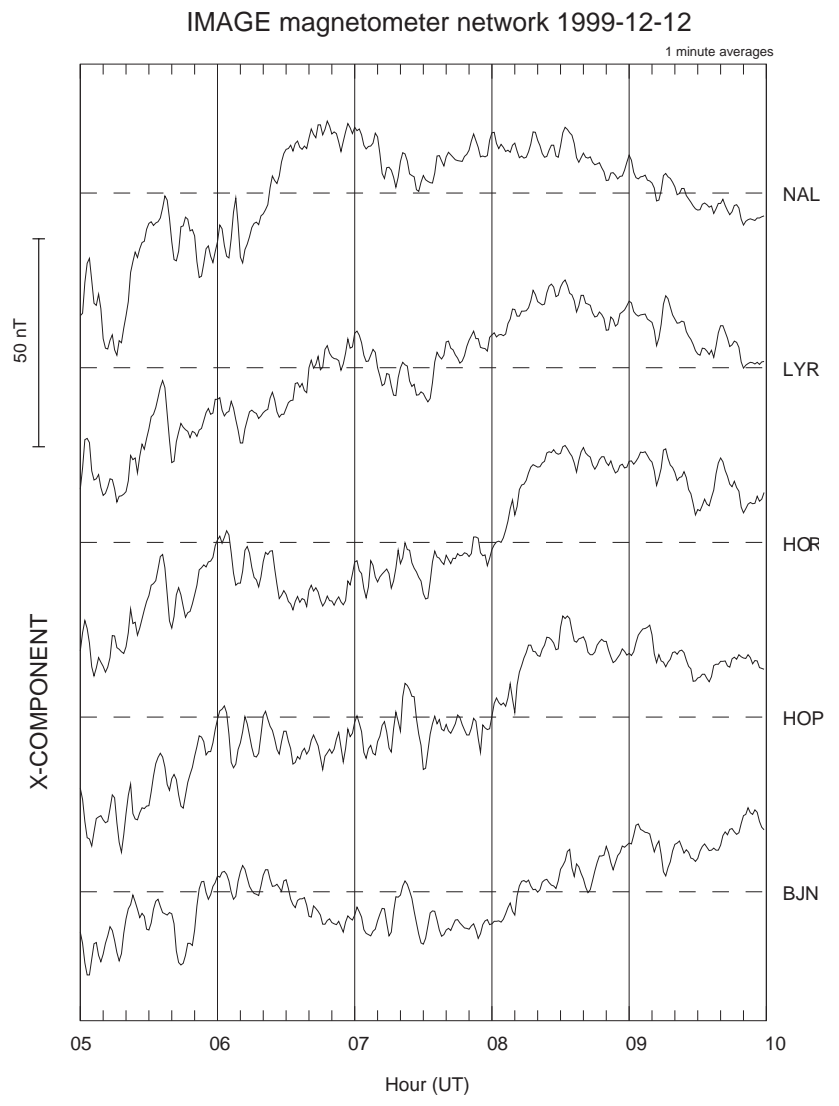

Fig. 23. X component magnetic deflections from the Svalbard IMAGE stations, spanning the latitude range from $76^{\circ}$ MLAT (NAL) to $71^{\circ}$ MLAT (BJN). The interval shown is 05:00-10:00 UT on 12 December 1999.

ity have been documented by Farrugia et al. (2003). Here we demonstrate the association with a plasma flow channel (marked FC in Fig. 24) and the DPY mode of magnetic deflection, a Svalgaard-Mansurov (S-M) effect. This association is schematically illustrated in Figs 13, 16, and 24. (v) A pulsating diffuse aurora (PDA) was observed in the 09:0010:00 MLT sector, on the equatorward side of the staircase cusp/BPS precipitation (Fig. 2). This is the CPS precipitation regime (Newell and Meng, 1994). (vi) PMAFs: While the discrete forms in the 09:00-10:00 MLT sector are moving predominantly eastward (noonward) and westward (antisunward) in the BPS and mantle regimes, respectively, the direction of auroral motion in the 10:00-11:00 MLT sector (at the westward boundary of the midday gap) is predominantly poleward, as also marked in Fig. 2. These forms (see Fig. 4) are poleward moving auroral forms (PMAFs) (Sandholt et al., 1986; Fasel, 1995; Sandholt et al., 2004). A second category of PMAFs consists of those appearing as a characteristic expansion across the 12:00 MLT meridian of brightening events originating in the postnoon sector (form $\mathrm{c}$ in Fig. 24). (vii) High-latitude form PA in the postnoon sector: This form (polar arc) is bordered on the poleward side by polar rain (PR) precipitation (Figs. 2 and 11). The on-

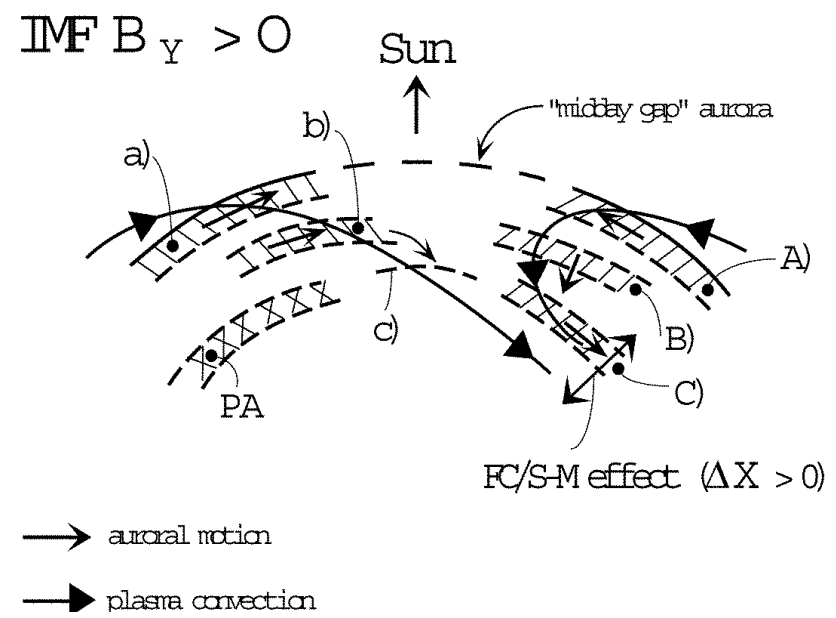

Fig. 24. Schematic illustration of the spatio-temporal evolution of the auroral brightening events. Successive activations of auroral forms in the pre- and postnoon sectors are marked A-B-C and a$\mathrm{b}-\mathrm{c}$, respectively. Auroral motions are indicated by arrows. Polar arc on the dusk side of the polar cap is marked PA. Plasma convection streamlines are superimposed. Plasma flow channel (FC) and associated Svalgaard-Mansurov effect $(\Delta X>0)$ are marked.

set of polar rain started immediately after satellite F13 exited a regime of polar cap arc precipitation on the postnoon side. The latter precipitation (PA) is that causing the postnoon sector auroral form marked (c) in Fig. 2 and crosshatched (PA) in Fig. 24. The associated magnetic deflection is called DPY2 in Fig. 13.

(III) Spatio-temporal structure:

Both the pre- and postnoon sector auroral activities are characterized by sequential activations of latitudinally separated forms. The activity is progressing from lower to higher latitudes. Thus, forms a-b-c and A-B-C represents different stages of evolution of the individual brightening events.

(IV) Equatorward boundary motions:

The motions of the auroral equatorward boundary observed during the interval 09:30-11:00 UT (see details in Fig. 8) are very similar to those observed in association with IMF northsouth rotations by Sandholt et al. (1998). With the present data set we document the detailed 2-D structure of the aurora in such cases (see Figs. 5 and 6). Thus, they are noonward moving brightening structures that are activated at successively higher latititude. The time scale of the equatorward expansions of the equatorward boundary $(\sim 15 \mathrm{~min})$ is similar to that predicted by the Cowley and Lockwood (1992) model for the ionospheric response to individual bursts of reconnection.

In the discussion below we want to highlight three aspects of the spatial structure of the dayside aurora and their implications for the solar wind-magnetosphere interconnection topology and momentum coupling along open field lines, applicable to intervals of southeast IMF orientation: (A) The greatest dayside auroral intensity and activity occur in the prenoon (08:00-11:00 MLT) and post- 

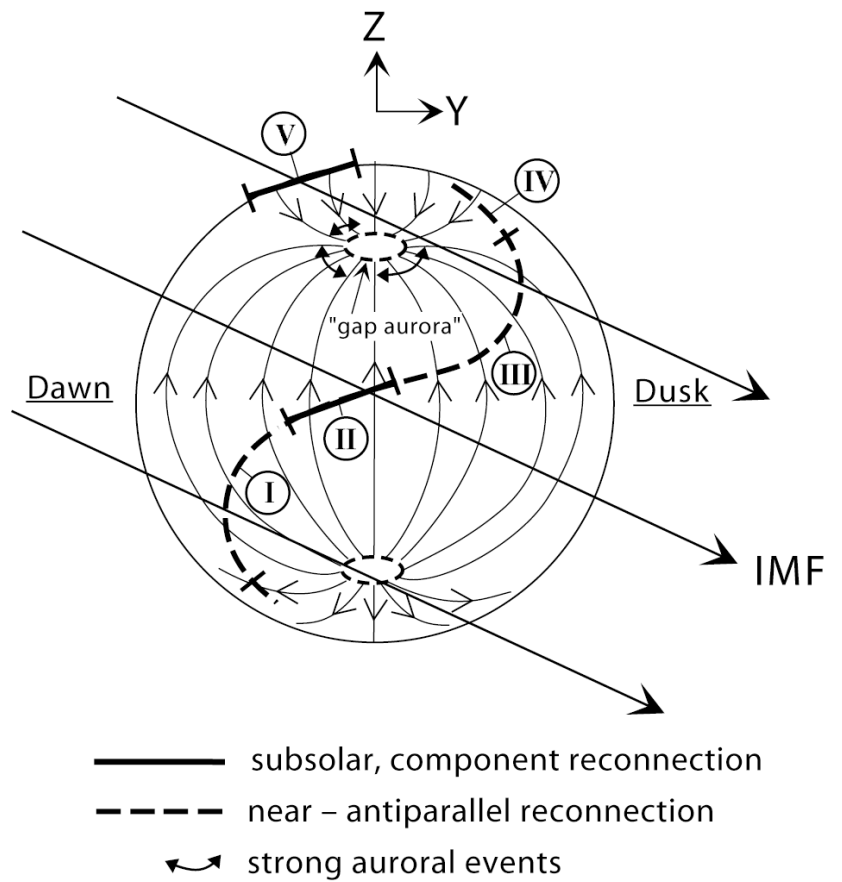

Fig. 25. Reconnection topology for a southeast directed IMF. The Earth's field (just inside the magnetopause) is indicated. The perspective is from the Sun towards the Earth. IMF field lines merging with the Earth's field in different sectors are superimposed. A tilted reconnection line, representing component reconnection at the subsolar, stagnant magnetopause (solid line; segment II) connects sectors favourable to antiparallel merging (dashed lines) at higher latitudes in the Southern (prenoon; segment I) and Northern (postnoon, III) Hemispheres. The stagnation point (magnetosheath flow) is shifted slightly to the prenoon side of the subsolar point. Regimes in the pre-and postnoon sectors, where strong auroral events are observed, as well as the "midday gap aurora" (within 11:00-12:00 MLT), have been marked. The high-latitude magnetopause in the postnoon-dusk and prenoon-dawn sectors are marked IV and V, respectively.

noon (12:00-16:00 MLT) sectors. (B) These auroral intensities/activities appear in sharp contrast to the weaker and more stable emission band in the "midday gap" within the 11:00-12:00 MLT sector. (C) The high-latitude aurora in the prenoon sector (IMF $B_{y}>0$ ) is associated with a strong convection channel/Svalgaard-Mansurov effect.

\section{Discussion}

4.1 Spatial structure of the dayside aurora: implications for IMF - magnetosphere interconnection topology

Figure 25 is a schematic illustration of a magnetopause reconnection topology applicable to our case of southeast IMF orientation (see, e.g. Moore et al., 2002). IMF field lines merging with the Earth's field in different sectors are indicated. While field lines marked I, II, and III are located on the equatorward (upstream) side of the cusp, field lines marked
IV and V are located on the downstream side of the cusp. Favourable sites of near-antiparallel reconnection (Luhmann et al., 1984) in the prenoon (Southern Hemisphere) and postnoon (Northern Hemisphere) sectors are marked by dashed lines in segments I and III, respectively. These sectors on the magnetopause map to sectors in the ionosphere where strong auroral brightening events are observed. The presence of strong field-aligned currents in these regions may be derived from the theory of Sonnerup and Siebert (2003) (see their Fig. 8).

It is our assumption that the midday gap aurora within the 11:00-12:00 MLT sector maps to the stagnant subsolar magnetopause (Spreiter et al., 1966), marked as II in Fig. 25, where the flow shears at the magnetopause and its transition boundary layer (TBL; Sonnerup and Siebert, 2003) are expected to be low compared to that on the pre- and postnoon flanks. Thus, the stagnant magnetosheath flow may explain the minimum in field-aligned current intensity (Iijima and Potemra, 1978; Potemra and Saflekos, 1979; Weimer, 2001) and auroral intensity observed at the cusp equatorward boundary around noon. Here we apply the same theory of FAC generation by flow shear (viscous stresses) in the open low latitude boundary layer, provided by Sonnerup and Siebert (2003).

The slight shift of the stagnation point towards the prenoon side, as predicted by gas dynamics (Russell et al., 1981), is consistent with our observations of the midday gap aurora and do support our interpretation. In our model of the reconnection topology (Fig. 25) the subsolar region is characterized by component reconnection (Moore et al., 2002). The presence of subsolar reconnection may be derived from the polar rain (Fairfield and Scudder, 1985) precipitation extending across the dayside polar cap in such cases, as documented in the DMSP F13 data shown in Figs. 11 and 21 (see also Sandholt and Farrugia, 2003, their Fig. 5).

4.2 Magnetosphere-ionosphere coupling on the downstream side of the cusp: aurora, plasma convection and field-aligned currents

The high-latitude sector marked IV in Fig. 25 is the site of possible lobe reconnection for our IMF orientation (Reiff and Burch, 1985; Crooker et al., 1998; Eriksson et al., 2003). It is possible that the postnoon-dusk sector auroral form crosshatched in Fig. 24 is an ionospheric manifestation of this process. Related to this we note that lobe reconnection for the actual IMF orientation (southeast) is widely considered to be a summer hemisphere phenomenon (Crooker and Rich, 1993; Weimer, 1995). In order to resolve this issue further study is needed.

The actual aurorae in the 13:00-16:00 MLT sector are located between the R1 FAC to the south and the regime of polar rain precipitation to the north (see Fig. 11). Similar precipitation features have in previous studies been attributed to lobe reconnection (Eriksson et al., 2002, 2003). The aurora in question may be associated with upward-directed Birkeland current resulting from current-continuity requirements 
in a region of flow shear (Reiff et al., 1978), as illustrated in Fig. 16.

A schematic view of the corresponding plasma circulation, as projected to the tail plasma sheet (the tail perspective), was given by Nishida et al. (1993) (see their Fig. 21). Thus, that figure may illustrate the plasma sheet sources of the observed particle precipitation in our postnoon-dusk sector auroral forms (a), (b), and (c). It is furthermore consistent with the plasma convection pattern indicated in Fig. 16. The detailed spatio-temporal structure of the aurora in this sector and its association with the plasma convection pattern is the topic of a separate paper in preparation.

The high-latitude sector marked V in Fig. 25 is the site of the solar wind-magnetosphere dynamo $(\boldsymbol{E} . \boldsymbol{J}<0)$ in the high-latitude boundary layer (HBL), on the downstream side of the cusp (Siscoe and Cummings, 1969; Stern, 1984; Siscoe et al., 1991). According to the model of Taguchi et al. (1993) there should be an IMF $B_{y}$-related dawn-dusk asymmetry in the location of the most effective HBL dynamo process. This is due to the effect of the magnetic curvature force acting on reconnected flux tubes (Jørgensen et al., 1972; Cowley, 1981; Gosling et al., 1990), which eventually leads to a dawn-dusk asymmetry in magnetosheath flow at the high-latitude magnetopause (Siscoe et al., 2000) with associated effects in mantle precipitation and field-aligned currents (Watanabe et al., 1996). Thus, the dawn sector is expected to be the favoured location for HBL dynamo action and mantle precipitation for positive IMF $B_{y}>0\left(B_{z}<0\right)$ conditions, as indicated in Fig. 25. The corresponding auroral forms/activities, typically appearing strongly within the $\sim 07: 00-10: 00 \mathrm{MLT} / 75-80^{\circ}$ MLAT sector, have been reported by Sandholt et al. (1993b), Sandholt et al. (1993a) and Farrugia et al. (2003). In this study we place this auroral phenomenon in the broader context of dayside auroral morphology and plasma convection.

The $\mathrm{C} 1 / \mathrm{C} 2$ pair of up- and downflowing field-aligned currents (Fig. 26) is coupled to the HBL dynamo as indicated by Taguchi et al. (1993) and Farrugia et al. (2003). The C1-C2 currents observed from Polar on 3 December 1997 (Farrugia et al., 2003) is schematically indicated in Fig. 13. The corresponding FAC current system and associated ionospheric flow channel for negative $B_{y}$ conditions, in that case located at the dusk side of the polar cap, have been documented in a recent study by Farrugia et al. (2004a). The pulsed nature of the corresponding aurora, in the form of a series of events/auroral forms moving eastward (tailward) at speeds of $1-2 \mathrm{~km} / \mathrm{s}\left(B_{y}<0 ; B_{z} \leq 0\right)$, poleward of the convection reversal in the postnoon sector, was reported by Farrugia et al. (1995). The latter case also demonstrates the IMF dependence.

In this study we documented the association between the ionospheric convection channel/ground magnetic deflection (DPY) and the aurora/particle precipitation (prenoon type $\mathrm{C}$ aurora) for the two $B_{y}>0$ cases on 3 December 1997 and 12 December 1999. The auroral brightening sequence in the morning sector (05:30-06:00 UT) on 3 December 1997 has been documented by Farrugia et al. (2003). The similar sequence of high-latitude brightening events for 12 Decem- ber 1999 is seen in Fig. 17a (the interval 05:30-06:20 UT). In Figs. 15 and 22 we report the corresponding convection channel and associated precipitation located in the $\sim 07: 00$ 09:00/75-80 ${ }^{\circ}$ MLAT sector. The ion drift speeds in this convection channel are much higher $(1-2 \mathrm{~km} / \mathrm{s})$ than the plateau of convection at speeds $\sim 0.5 \mathrm{~km} / \mathrm{s}$ observed in the central polar cap.

While the strong convection channel is located on the dawn side of the polar cap for IMF $B_{y}>0$ it is located on the dusk side for $B_{y}<0$ conditions. Early observations of IMF $B_{y}$-related asymmetric polar cap convection were reported by Heppner (1972) and Mozer et al. (1974). Here we document a case when the convection in the central polar cap is weak, while a strong convection channel is present at the polar cap boundary (Fig. 22).

The first documentation of the association between a specific auroral activity, i.e. that referred to as the category $2 / 3$ PMAFs by Fasel (1995), and this convection channel was reported by Sandholt et al. (1993a). At that time we speculated that it was coupled to the high-latitude boundary layer (HBL). At this stage we can conclude that this convection channel is powered by the solar wind-magnetosphere dynamo in the HBL (Farrugia et al., 2004a). This observation re-establishes the HBL dynamo region (Stern, 1984) as an important source of momentum transfer to the polar cap along old open flux tubes, downstream of the cusp. Recent observations of high-speed flows (pulsed ionospheric flows; PIFs) on the downstream side of the cusp (Provan et al., 2002) are in agreement with the present observations. This convection feature, extending to the dawn-dusk terminator, is in sharp contrast to the traditional open field line model of magnetosphere, claiming that "only newly-opened flux tubes are effective in generating flow in the ionosphere" (Lockwood et al., 1990). The present study shows that the auroral precipitation in the regime of the convection channel at 0700 MLT consists of a $5^{\circ}(500 \mathrm{~km})$ wide zone of structured precipitation (see Fig. 22). The associated ground magnetic deflection (Fig. 23) is that often referred to as DPY or the Svalgaard-Mansurov effect (Svalgaard, 1973, 1975).

The source of the Svalgaard-Mansurov effect in terms of solar wind-magnetosphere-ionosphere (SW-M-I) coupling, i.e. the association with field-aligned currents and auroral precipitation, has not been established until our recent papers. In the early paper by Heppner (1972) it is stated that "the correlations between polar cap electric field distributions and the interplanetary magnetic field presented here do not suggest any direct relationship with particle entry into, or acceleration within, the magnetosphere, particularly in view of the apparent lack of correlation between the form of the electric field distribution and the level of magnetic disturbance." At present we may conclude that the associations between the following essential elements of the SW-M-I coupling process have been established: (i) the DPY magnetic deflection, (ii) the convection channel at the polar cap boundary, (iii) the auroral precipitation (see Figs. 16 and 22), (iv) the field-aligned current structure (Farrugia et al., 2003), and (v) the association with momentum transfer events in the 
high-latitude boundary layer, downstream of the cusp (Farrugia et al., 2004a).

Figure 26 shows a schematic, conceptual model of the C1/C2 Birkeland currents with their associated closure currents at high (HBL) and low (ionospheric Pedersen current) altitudes. This current circuit is responsible for momentum transfer to the type 2 convection channel threaded by old open field lines (marked red). Field-aligned current $\mathrm{C} 1$ is accompanied by the aurora we refer to as type C (Fig. 24). Also shown are dayside region $1 / 2$ field-aligned currents and associated convection channels called type 1 (see Potemra and Saflekos, 1979). The latter convection, threaded by newly open field lines, is accompanied by the auroral brightening forms in the pre- and postnoon sectors which we refer to as $\mathrm{A}-\mathrm{B}$, and $\mathrm{a}-\mathrm{b}$, respectively (see Fig. 24). The association between dayside aurora and R1 field-aligned currents has been documented in a recent case study by Farrugia et al. (2004b). Trajectories/positions of spacecraft Polar and Cluster/FAST during ground-satellite conjunctions discussed by Farrugia et al. (2003) and Farrugia et al. (2004a), respectively, are also indicated in the schematic figure.

\subsection{Conclusions}

Finally, we summarize the main conclusions derived from this case study:

1. We distinguish between distinctly different stages of auroral activity/momentum transfer/FACs along open field lines, corresponding to the different positions of the field line with respect to the cusp magnetic bifurcation line (newly-open vs. old open field lines). This scenario of two-stage momentum transfer along open field lines is consistent with the multiple branch open field line model of Vasyliunas (1995).

2. The stable "midday gap" aurora (Fig. 20) and the much stronger brightening events in the pre- and postnoon sectors are magnetically coupled to different reconnection sites and different reconnection modes.

3. The midday gap maps to the subsolar region where the sheath flow is stagnant and the reconnection process is of the component type.

4. The strong auroral brightening events threaded by newly-open field lines in the pre- and postnoon sectors (A-B/a-b: noonward moving brightening structures activated at successively higher latitudes during the individual events) are signatures of reconnection events that are initiated well away from the subsolar point, presumably by antiparallel reconnection at high Southern and Northern Hemisphere magnetopause latitudes in the pre- and postnoon sectors, respectively.

5. The near-simultaneous brightenings of aurorae on either side of the "gap" (AB east and AB west) indicates that reconnection transients are activated nearsimultaneously on both sides of the stagnation point.
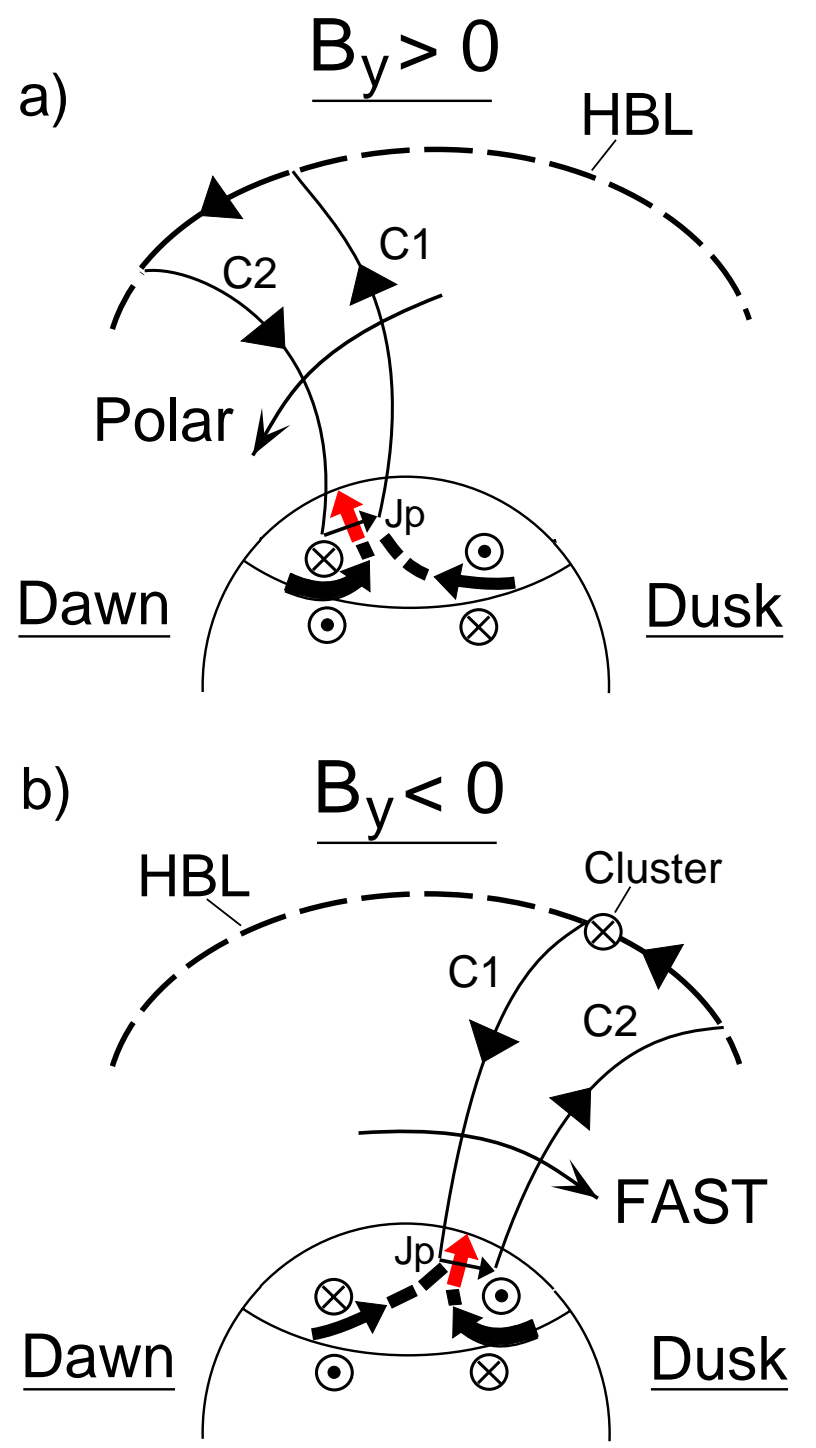

\section{$\rightarrow$ Convection channels 1 $\rightarrow$ Convection channels 2 $\otimes$ FAC down $\odot$ FAC up}

Fig. 26. Schematic illustration of dayside field-aligned current systems and plasma convection corresponding to the auroral morphology documented in this paper. The IMF $B_{y}>0$ case is shown in the upper panel. Dayside R1/R2 currents is associated with type 1 convection channel threaded by newly-open field lines. The C1/C2 FACs are threaded by old open field lines on the downstream side of the cusp. The closure of the latter currents at high and low altitudes are indicated. The associated type 2 convection channel in the polar cap is marked red. The IMF $B_{y}<0$ case is shown in the lower panel. Trajectories of spacecraft Polar, FAST and Cluster used to document these currents are indicated. 
6. Auroral form C (Fig. 24), appearing as a sequence of high-latitude brightening events, and the strong flow channel located at the dawn side polar cap boundary (for positive IMF $B_{y}$ conditions) are manifestations of high-latitude momentum transfer events along old open magnetic field lines, on the downstream side of the cusp. The associated DPY magnetic deflection is a SvalgaardMansurov effect.

7. The high-latititude form on the postnoon-dusk side is accompanied by a specific precipitation signature labelled polar arc (PA) in Fig. 16. It is a result of current continuity requirements in a region of flow shear, as explained by Reiff et al. (1978).

Acknowledgements. The Wind data are courtesy of R. P. Lepping and K. W. Ogilvie. We thank B. Lybekk and E. Trondsen for technical assistance during the auroral observation campaigns in Ny Ålesund, and with the presentation of the optical data. The auroral observation program on Svalbard is supported by the Norwegian Research Council, the Norwegian Polar Research Institute and AFOSR Task 2311AS. This work is supported in part by NASA Living with a Star grant NAG5-12189, NASA Wind grant NAG511803, and NASA Polar grant NAG5-11676.

Topical Editor T. Pulkkinen thanks C. Deehr and S. Orsini for their help in evaluating this paper.

\section{References}

Chisham, G., Coleman, I. J., Freeman, M. P., Pinnock, M., and Lester, M.: Ionospheric signatures of split reconnection $\mathrm{x}$ lines during conditions of IMF $B_{z}<0$ and $\left|B_{y}\right| \sim\left|B_{z}\right|$ : Evidence for the antiparallel merging hypothesis, J. Geophys. Res., 107(A10),1323, doi:10.1029/2001JA009, 124, 2002a.

Chisham, G., Pinnock, M., Coleman, I. J., Hairston, M. R., and Walker, A. D. M.: An unusual geometry of the ionospheric signature of the cusp: implications for magnetopause merging sites, Ann. Geophys., 20, 29, 2002 b.

Coleman, I. J., Chisham, G., Pinnock, M., and Freeman, M. P.: An ionospheric convection signature of antiparallel reconnection, J. Geophys. Res., 106, 28 995, 2001.

Cowley, S. W. H.: Comments on the merging of non-antiparallel magnetic fields, J. Geophys. Res., 81, 3455, 1976.

Cowley, S. W. H.: Magnetospheric asymmetries associated with the Y-component of the IMF, Planet. Space Sci., 29, 79, 1981.

Cowley, S. W. H.: The causes of convection in the Earth's magnetosphere: A review of developments during the IMS, Rev. Geophys., 20, 531, 1982.

Cowley, S. W. H. and Lockwood, M.: Excitation and decay of solar wind-driven flows in the magnetosphere-ionosphere system, Ann. Geophys., 10, 103, 1992.

Cowley, S. W. H., Morelli, J. P., and Lockwood, M.: Dependence of convective flows and particle precipitation in the high-latitude dayside ionosphere on the $\mathrm{X}$ and $\mathrm{Y}$ components of the interplanetary magnetic field, J. Geophys. Res., 96, 5557, 1991.

Crooker, N. U.: Dayside merging and cusp geometry, J. Geophys. Res., 84, 951, 1979.

Crooker, N. U. and Rich, F. J.: Lobe cell convection as a summer phenomenon, J. Geophys. Res., 98, 13 403, 1993.
Crooker, N. U., Lyon, J. G., and Fedder, J. A.: MHD model merging with IMF $B_{y}$ : Lobe cells, sunward polar cap convection, and overdraped lobes, J. Geophys. Res., 103, 9143, 1998.

Eriksson, S., Bonnell, J. W., Blomberg, L. G., Ergun, R. E., Marklund, G. T., and Carlson, C. W.: Lobe cell convection and fieldaligned currents poleward of the Region 1 current system, J. Geophys. Res., 107 (A8), 1185, doi:10.1029/2001JA005041, 2002.

Eriksson, S., Peria, W. J., Bonnell, J. W. Su, Y. J., Ergun, R. E., Tung, Y. K., Parks, G. K., and Carlson, C. W.: Lobe cell convection and polar cap precipitation, J. Geophys. Res., 108 (A5), 1198, doi:10.1029/2002JA009725, 2003.

Fairfield, D. H. and Scudder, J. D.: Polar rain: Solar coronal electrons in the earth's magnetosphere, J. Geophys. Res., 90, 4055, 1985.

Farrugia, C. J., Sandholt, P. E., Cowley, S. W. H., Southwood, D. J., Egeland, A., Stauning, P., Lepping, R. P., Lazarus, A. J., and Hansen, T.: Reconnection - associated auroral activity stimulated by two types of upstream dynamic pressure variations: Interplanetary magnetic field $B_{z} \sim 0, B_{y}<0$ case, J. Geophys. Res. 100, $21753,1995$.

Farrugia, C. J., Sandholt, P. E., Maynard, N. C., Torbert, R. B., and Ober, D. M.: Temporal variations in a four-sheet fieldaligned current system and associated aurorae as observed during a Polar-ground magnetic conjunction in the midmorning sector, J. Geophys. Res., 108(A6), 1230, doi:10.1029/2002JA009619, 2003.

Farrugia, C. J., Lund, E. J., Sandholt, P. E., Wild, J., Cowley, S. W. H., Balogh, A., Moikis, C., Moebius, E., Dunlop, M. W., Bosqued, J.-M., Carlsson, C. W., Parks, G. K., Cerisier, J.C., Kelly, J. D., Sauvaud, J.-A., Rème, H., and Evans, D. S.: Pulsed flows at the high-altitude cusp poleward boundary, and associated ionospheric convection and particle signatures, during a CLUSTER-FAST-SuperDARN-Søndrestrøm conjunction under a southwest IMF, Ann. Geophys., 22, 2891-2905, 2004a.

Farrugia, C. J., Sandholt, P. E., Torbert, R. B., and Østgaard, N.: Temporal and spatial aspects of the cusp inferred from local and global ground- and space-based observations in a case study, J. Geophys. Res., 109, A04209, doi:10.1029/2003JA010121, 2004b.

Fasel, G.: Dayside poleward moving auroral forms: A statistical study, J. Geophys. Res., 100, 11 891, 1995.

Friis-Christensen, E.: Polar cap current systems, in: Magnetospheric Currents, edited by Potemra, T. A., vol. 28, Geophysical Monograph, AGU, Washington, D.C., 86-95, 1984.

Friis-Christensen, E. and Wilhjelm, J.: Polar cap currents for different directions of the interplanetary magnetic field in the $\mathrm{Y}-\mathrm{Z}$ plane, J. Geophys. Res., 80, 1248, 1975.

Gonzalez, W. D. and Mozer, F.: A quantitative model for the potential resulting from reconnection with an arbitrary interplanetary magnetic field, J. Geophys. Res., 79, 4186, 1974.

Gosling, J. T., Thomsen, M. F., Bame, S. J., Elphic, R. C., and Russell, C. T.: Plasma flow reversals at the dayside magnetopause and the origin of asymmetric polar cap convection, J. Geophys. Res., 95, 8073, 1990.

Haerendel, G., Paschmann, G., Sckopke, N., Rosenbauer, H., and Hedgecock, P. C.: The frontside boundary layer and the problem of reconnection, J. Geophys. Res., 83, 3195, 1978.

Heppner, J. and Maynard, N. C.: Empirical high-latitude electric field models, J. Geophys. Res., 92, 4467-4489, 1987.

Heppner, J. P.: Polar-cap electric field distributions related to the interplanetary magnetic field direction, J. Geophys. Res., 77, 4877, 1972. 
Hill, T.: Magnetic merging in a collisionless plasma, J. Geophys. Res., 80, 4689, 1975.

Iijima, T. and Potemra, T.: Large scale characteristics of fieldaligned currents associated with substorms, J. Geophys. Res., 83, 599, 1978.

Jørgensen, T. S., Friis-Christensen, E., and Wilhjelm, J.: Interplanetary magnetic field direction and high-latitude ionospheric currents, J. Geophys. Res., 77, 1976, 1972.

Lee, L. C. and Fu, Z. F.: A theory of flux transfer at the magnetopause, Geophys. Res. Lett., 12, 105, 1985.

Lockwood, M., Cowley, S. W. H., and Freeman, M. P.: The excitation of plasma convection in the high-latitude ionosphere, J. Geophys. Res., 95, 7061, 1990.

Lockwood, M., Lanchester, B. S., Frey, H. U., Throp, K., Morley, S. K., Milan, S. E., and Lester, M.: IMF control of cusp proton emission intensity and dayside convection: implications for component and anti-parallel reconnection, Ann. Geophys., 21, 2003

Luhmann, J. G., Walker, R. J., Russell, C. T., Crooker, N. U., Spreiter, J. R., and Stahara, S. S.: Patterns of potential magnetic field merging sites on the dayside magnetopause, J. Geophys. Res., 89, 1739, 1984.

Lyons, L. R., Lu, G., de la Beaujardiere, O., and Rich, F. J.: Synoptic maps of polar caps for stable interplanetary magnetic field intervals during January 1992 geospace environment modeling campaign, J. Geophys. Res., 101, 27 283, 1996.

Lyons, L. R., Koskinen, H. E. J., Blake, J. B., Egeland, A., Hirahara, M., Øieroset, M., Sandholt, P. E., and Shiokawa, K.: Processes Leading to Plasma Losses into the High-Latitude Atmosphere, vol. 6, chap. 3, Science Series of ISSI, Kluwer Academic Publisher, Dordrecht, Holland, 85-135, 1999.

Maynard, N. C., Burke, W. J., Sandholt, P. E., Moen, J., Ober, D. M., Lester, M., Weimer, D. R., and Egeland, A.: Observations of simultaneous effects of merging in both hemispheres, J. Geophys. Res., 106, 24 551, 2001.

Maynard, N. C., Ober, D. M., Burke, W. J., Scudder, J. D., Lester, M., Dunlop, M., Wild, J. A., Grocott, A., Farrugia, C. J., Lund, E. J., Russell, C. T., Weimer, D. R., Siebert, K. D., Balogh, A., Andre, M., and Rème, H.: Polar, cluster and superdarn evidence for high-latitude merging during southward imf: temporal/spatial evolution, Ann. Geophys., 21, 2233, 2003.

Milan, S., Lester, M., Cowley, S. W. H., and Brittnacher, M.: Convection and auroral response to a southward turning of the IMF: Polar UVI, CUTLASS and IMAGE signatures of transient flux transfer at the magnetopause, J. Geophys. Res., 105, 15741, 2000

Moore, T. E., Fok, M.-C., and Chandler, M. O.: The dayside reconnection X line, J. Geophys. Res., 107 (A10), 1332, doi:10.1029/2002JA009381, 2002.

Mozer, F. S., Gonzalez, W. D., Bogott, F., Kelley, M. C., and Schutz, S.: High-latitude electric fields and the three-dimensional interaction between the interplanetary and terrestrial magnetic fields, J. Geophys. Res., 79, 56, 1974.

Neudegg, D. A., Cowley, S. W. H., McWilliams, K. A., Lester, M., Yeoman, T. K., Sigwarth, J., Haerendel, G., Baumjohann, W., Auster, U., Fornacon, K.-H., and Georgescu, E.: The UV aurora and ionospheric flows during flux transfer events, Ann. Geophys., 19, 179, 2001.

Newell, P. T. and Meng, C.-I.: Ionospheric projection of magnetospheric regions under low and high solar wind pressure conditions, J. Geophys. Res., 99, 273, 1994.

Newell, P. T., Sibeck, D. G., and Meng, C.-I.: Penetration of the interplanetary magnetic field $B_{y}$ and magnetosheath plasma into the magnetosphere: Implications for the predominant merging site, J. Geophys. Res., 100, 235, 1995.

Nishida, A. T., Mukai, T., Hayakawa, H., Matsuoka, A., Tsuruda, K., Kaya, N., and Fukunishi, H.: Unexpected features of the ion precipitation in the so-called cleft/low-latitude boundary layer: Association with sunward convection and occurrence of open field lines, J. Geophys. Res., 98, 11 161, 1993.

Paschmann, G., Sckopke, N., Haerendel, G., Papamastorakis, J., Bame, S. J., Asbridge, J. R., Gosling, J. T., Hones Jr., E. W., and Tech, E. R.: ISEE plasma observations near the subsolar magnetopause, Space Sci. Rev., 22, 717, 1978.

Paschmann, G., Sonnerup, B. U. Ö., Papamastorakis, I., Sckopke, N., Haerendel, G., Bame, S. J., Asbridge, R., Gosling, J. T., Russell, C. T., and Elphic, R. C.: Plasma acceleration at the Earth's magnetopause: Evidence for reconnection, Nature, 282, 243, 1979.

Paschmann, G., Haerendel, G., Papamastorakis, I., Sckopke, N., Bame, S. J., and Gosling, J. T.: Plasma and magnetic field characteristics of magnetic flux transfer events, J. Geophys. Res., 87, 2159, 1982.

Peroomian, V.: The influence of the interplanetary magnetic field on the entry of solar wind ions into the magnetosphere, Geophys. Res. Lett., 30 (7), 1407, doi:10.1029/2002GL016627, 2003.

Phan, T. D. and Paschmann, G.: Low-latitude dayside magnetopause and boundary layer for high magnetic shear 1 . structure and motion, J. Geophys. Res., 101, 7801, 1996.

Potemra, T. A. and Saflekos, N. A.: Birkeland currents and the interplanetary magnetic field, in: Magnetospheric Boundary Layers, edited by Battrick, B., ESA SP-148, Noordwijk, Netherlands, 193-198, 1979.

Provan, G., Milan, S. E., Lester, M., Yeoman, T. K., and Khan, H.: Simultaneous observations of the ionospheric footprint of flux transfer events and dispersed ion signatures, Ann. Geophys., 20, $281,2002$.

Reiff, P. H. and Burch, J. L.: IMF $\mathrm{B}_{\mathrm{y}}$-dependent dayside plasma flow and Birkeland currents in the dayside magnetosphere, 2, A global model for northward and southward IMF, J. Geophys. Res., 90, 1595, 1985.

Reiff, P. H., Burch, J. L., and Heelis, R. A.: Dayside auroral arcs and convection, Geophys. Res. Lett., 5, 391, 1978.

Rijnbeek, R. P.: Flux transfer events: Impulsive reconnection signatures at the Earth's magnetopause, Ph.D. thesis, Physics Dept., Imperial College of Science and Technology, London, 1984.

Rodger, A. S., Chisham, G., Coleman, I. J., Freeman, M. P., and Pinnock, M.: Anti-parallel reconnection at the dayside magnetopause: Ionospheric signatures and implications for the lowlatitude boundary layer, in: Earth's Low-Latitude Boundary Layer, edited by Newell, P. T. and Onsager, T., vol. 133, Geophysical Monograph, AGU, Washington D.C., 311-318, 2003.

Russell, C. T.: The structure of the magnetopause, Planet. Space Sci., 51, 731, 2003.

Russell, C. T. and Elphic, R. C.: Initial ISEE magnetometer results: Magnetopause observations, Space Sci. Rev., 22, 681, 1978.

Russell, C. T., Zhuang, H.-C., and Walker, R.: A note on the location of the stagnation point in the magnetosheath, Geophys. Res. Lett., 8, 984, 1981.

Sandholt, P. E. and Farrugia, C. J.: Does the aurora provide evidence for the occurrence of antiparallel magnetopause reconnection?, J. Geophys. Res., 108, 2003.

Sandholt, P. E., Deehr, C. S., Egeland, A., Lybekk, B., Viereck, R., and Romick, G. J.: Signatures in the dayside aurora of plasma 
transfer from the magnetosheath, J. Geophys. Res., 91, 10063 , 1986.

Sandholt, P. E., Lockwood, M., Oguti, T., Cowley, S. W. H., Freeman, K. S. C., Lybekk, B., Egeland, A., and Willis, D. M.: Midday auroral breakup events and related energy and momentum transfer from the magnetosheath, J. Geophys. Res., 95, 1039, 1990.

Sandholt, P. E., Moen, J., Opsvik, D., Denig, W. F., and Burke, W. J.: Auroral event sequence at the dayside polar cap boundary: Signature of time-varying solar wind-magnetosphere-ionosphere coupling, Adv. Space Res., 13 (4), 7, 1993a.

Sandholt, P. E., Moen, J., Rudland, A., Opsvik, D., Denig, W. F., and Hansen, T.: Auroral event sequences at the dayside polar cap boundary for positive and negative interplanetary magnetic field $B_{y}$, J. Geophys. Res., 98, 7737, 1993b.

Sandholt, P. E., Farrugia, C. J., Moen, J., and Cowley, S. W. H.: Dayside auroral configurations: Responses to southward and northward rotations of the interplanetary magnetic field, J. Geophys. Res., 103, $20279,1998$.

Sandholt, P. E., J., M., Farrugia, C. J., Cowley, S. W. H., Lester, M., Milan, S. E., Valladares, C., Denig, W. F., and Eriksson, S.: Multi-site observations of the association between aurora and plasma convection in the cusp/polar cap during a south-eastward $\left(B_{y} \simeq\left|B_{z}\right|\right)$ IMF orientation, Ann. Geophys., 21, 539, 2003.

Sandholt, P. E., Farrugia, C. J., and Denig, W. F.: Dayside aurora and the role of IMF $\left|B_{y} / B_{z}\right|$ : detailed morphology and response to magnetopause reconnection, Ann. Geophys., 22, 613, 2004.

Saunders, M. A., Russell, C. T., and Sckopke, N.: Flux transfer events: Scale size and interior structure, Geophys. Res. Lett., 11, 131, 1984.

Siscoe, G. L. and Cummings, W. D.: On the cause of geomagnetic bays, Planet. Space Sci., 17, 1795, 1969.

Siscoe, G. L., Lotko, W., and Sonnerup, B. U. Ö.: A high-latitude, low-latitude boundary layer model of the convection current system, J. Geophys. Res., 96, 3487, 1991.

Siscoe, G. L., Erickson, G. M., Sonnerup, B. U. Ö., Maynard, N. C., Siebert, K. D., Weimer, D. R., and White, W. W.: Deflected magnetosheath flow at the high-latitude magnetopause, J. Geophys. Res., 105, 12 851, 2000.

Siscoe, G. L., Erickson, G. M., Sonnerup, B. U. Ö., Maynard, N. C., Siebert, K. D., Weimer, D. R., and White, W. W.: Global role of $E_{\|}$in magnetopause reconnection: An explicit demonstration, J. Geophys. Res., 106, 13 015, 2001.

Sonnerup, B. U. O.: Magnetopause reconnection rate, J. Geophys. Res., 79, 1546, 1974.
Sonnerup, B. U. Ö. and Siebert, K. D.: Theory of the low-latitude boundary layer and its coupling to the ionosphere: A tutorial review, in: Earth's Low-Latitude Boundary Layer, edited by Newell, P. T. and Onsager, T., vol. 133, Geophysical Monograph, 13-32, AGU, Washington, D.C., 2003.

Sonnerup, B. U. Ö., Paschmann, G., Papamastorakis, I., Sckopke, N., Haerendel, G., Bame, S. J., Asbridge, J. R., Gosling, J. T., and Russell, C. T.: Evidence for magnetic reconnection at the Earth's magnetopause, J. Geophys. Res., 86, 10 049, 1981.

Spreiter, J. R., Summers, A. L., and Alksne, A. Y.: Hydrodynamic flow around the magnetosphere, Planet. Space Sci., 14, 223, 1966.

Stern, D. P.: Magnetospheric dynamo processes, in: Magnetospheric Currents, edited by Potemra, T. A., vol. 28, Geophys. Monogr., AGU, Washington, D.C., 200-207, 1984.

Svalgaard, L.: Polar cap magnetic variations and their relationship with the interplanetary magnetic sector structure, J. Geophys. Res., 78, 2064, 1973.

Svalgaard, L.: On the use of Godhavn H component as an indicator of the interplanetary sector polarity, J. Geophys. Res., 80, 2717, 1975.

Taguchi, S., Sugiura, M., Winningham, J. D., and Slavin, J.: Characterization of the IMF $B_{y}$-dependent field-aligned currents in the cleft region based on DE 2 observations, J. Geophys. Res., 98, 1393, 1993.

Tsyganenko, N. A.: Effects of the solar wind conditions on global magnetospheric configuration as deduced from data-bases field models, in Proceedings of the ICS-3 Conference on Substorms, no. 389, ESA SP, 181, 1996.

Vasyliunas, V. M.: Multiple-branch model of the open magnetopause, Geophys. Res. Lett., 22, 1145, 1995.

Watanabe, M., Iijima, T., and Rich, F. J.: Synthesis models of dayside field-aligned currents for strong interplanetary magnetic field $B_{y}$, J. Geophys. Res., 101, 13, 303, 1996.

Weimer, D. R.: Models of high-latitude electric potentials derived with a least error fit of spherical harmonic coefficients, J. Geophys. Res., 100, 19595, 1995.

Weimer, D. R.: Maps of ionospheric field-aligned currents as a function of the interplanetary magnetic field derived from Dynamics Explorer 2 data, J. Geophys. Res., 106, 12 889, 2001.

White, W., Siscoe, G. L., Erickson, G. M., Kaymaz, Z., Maynard, N. C., Siebert, K. D., Sonnerup, B. U. Ö., and Weimer, D. R.: The magnetospheric sash and the cross-tail S, Geophys. Res. Lett., 25, 1605, 1998. 